
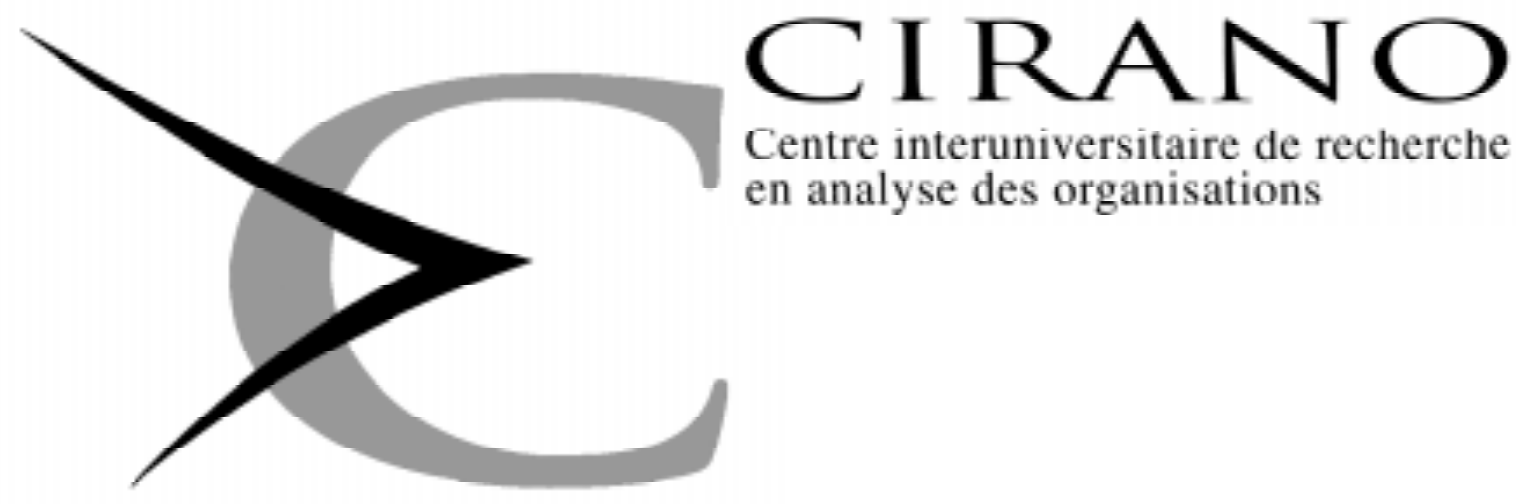

Centre interuniversitaire de recherche en analyse des organisations

Série Scientifique

Scientific Series

95s-13

Higher Moment Estimators for

Linear Regression Models with

Errors in the Variables

Marcel G. Dagenais, Denise L. 


\section{CIRANO}

Le CIRANO est une corporation privée à but non lucratif constituée en vertu de la Loi des compagnies du Québec. Le financement de son infrastructure et de ses activités de recherche provient des cotisations de ses organisations-membres, d'une subvention d'infrastructure du ministère de l'Industrie, du Commerce, de la Science et de la Technologie, de même que des subventions et mandats obtenus par ses équipes de recherche. La Série Scientifique est la réalisation d'une des missions que s'est données le CIRANO, soit de développer l'analyse scientifique des organisations et des comportements stratégiques.

CIRANO is a private non-profit organization incorporated under the Québec Companies Act. Its infrastructure and research activities are funded through fees paid by member organizations, an infrastructure grant from the Ministère de l'Industrie, du Commerce, de la Science et de la Technologie, and grants and research mandates obtained by its research teams. The Scientific Series fulfils one of the missions of CIRANO: to develop the scientific analysis of organizations and strategic behaviour.

\section{Les organisations-partenaires / The Partner Organizations}

-Ministère de l'Industrie, du Commerce, de la Science et de la Technologie.

-École des Hautes Études Commerciales.

-École Polytechnique.

-Université de Montréal.

-Université Laval.

-McGill University.

-Université du Québec à Montréal.

-Bell Québec.

-La Caisse de dépôt et de placement du Québec.

-Hydro-Québec.

-Fédération des caisses populaires de Montréal et de l'Ouest-du-Québec.

-Téléglobe Canada.

-Société d'électrolyse et de chimie Alcan Ltée.

-Avenor.

-Service de développement économique de la ville de Montréal.

-Raymond, Chabot, Martin, Paré

-Banque Nationale du Canada

Ce document est publié dans l'intention de rendre accessibles les résultats préliminaires de la recherche effectuée au CIRANO, afin de susciter des échanges et des suggestions. Les idées et les opinions émises sont sous l'unique responsabilité des auteurs, et ne représentent pas nécessairement les positions du CIRANO ou de ses partenaires.

This paper presents preliminary research carried out at CIRANO and aims to encourage discussion and comment. The observations and viewpoints expressed are the sole responsibility of the authors. They do not necessarily represent positions of CIRANO or its partners.

ISSN 1198-8177 


\title{
HIGHER MOMENT ESTIMATORS FOR LINEAR REGRESSION MODELS WITH ERRORS IN THE VARIABLES
}

\author{
Marcel G. Dagenais ${ }^{1} *$ and Denyse L. Dagenais ${ }^{2}$ \\ 1 \\ Centre de recherche et developpement en economique (C.R.D.E.), Departement des sciences \\ economiques, Universite de Montreal et Centre interuniversitaire de recherche en analyse des \\ organisations (CIRANO), Montreal (Quebec) Canada. \\ 2 \\ Institut d'economie appliquee, Ecole des Hautes Etudes Commerciales, Montreal (Quebec) \\ H3T 1V6, Canada.
}

\begin{abstract}
This paper proposes consistent instrumental variable estimators for linear regression models with errors in the variables that require no extraneous information. These estimators are based on sample moments of order higher than two. While similar estimators proposed previously in the literature seem to be quite erratic, our experimental findings suggest that our estimators perform better than ordinary least squares estimators in terms of root mean squared errors and also in terms of size of type I errors of standard tests in many typical situations of economic analyses. Tests for the presence of errors in the variables are also described.
\end{abstract}

Key words : errors in the variables; measurement errors; higher moments; instrumental variables.

JEL classification : C13, C49.

* C.R.D.E./Universite de Montreal, C.P. 6128, Succursale Centre-ville, Montreal (Quebec) H3C 3J7 Canada, tel : (514) 343-6760; fax : (514) 343-5831. 


\section{INTRODUCTION}

Most data used in empirical analyses contain errors of measurement. Such errors are probably relatively more important in macroeconomic studies [Morgenstern (1963), Langanskens and Van Rickeghem (1974), Dagenais (1992)], but they are also present in most microeconomic analyses [Rodgers, Brown and Duncan (1993); Duncan and Hill (1985); Altonji and Siow (1987)]. Although the early econometricians insisted greatly on the presence of errors in the variables, this phenomenon has not been strongly emphasized in the ensuing developments of the discipline [Goldberger (1972); Morgenstern (1963); Griliches and Hausman (1986); Griliches (1986)].1 In the present state of the art, most econometric textbooks contain a rather short section where it is demonstrated that in linear regression models, errors in the explanatory variables lead to inconsistent ordinary least squares (OLS) estimators. Unless information is available on the variances of these errors, authors suggest essentially the use of instrumental variables [Fuller (1987), Bowden (1984), Aigner et al. (1984)] to obtain consistent estimators. Despite the fact that in applied papers authors often warn the reader that

We thank Eric Ghysels, Christian Gourieroux, Jerry Hausman, Linda Khalaf and James MacKinnon for several useful comments. We also benefited from the research assistance of Christine Lamarre and, in the early phase of the study, from that of Marie-Josephine Nsengiyumva and Jean Lavoie. Different phases of this research project were supported alternatively by the Natural Sciences and Engineering Research Council of Canada, the Social Sciences and Humanities Research Council of Canada, the Fonds pour la formation de chercheurs et l'aide a la recherche of Quebec, the Fonds Marcel-Faribault of the Universite de Montreal and the Fonds PARADI granted to the Universite de Montreal by the Canadian International Development Agency. We are grateful to two anonymous referees who made very useful suggestions.

1 Adverse effects of the presence of errors in the variables in regression models with autocorrelated errors have been underlined in Dagenais (1994) and Grether and Maddala (1973). 
the possible presence of errors in the variables may bias the results, in many cases, no special effort is made to resort to instrumental variable techniques to reduce the possible biases and no special step is taken to test for the presence of errors in the variables (EV) using, for example, Hausman's (1978) instrumental variable test. The attitude of most applied researchers is probably due, in a number of cases, to the fact that it is not always easy to verify that the available instrumental variables satisfy the required conditions to justify their use [Pal (1980)]. In other cases, the eligible instruments may simply not be easily accessible to the researcher [Klepper and Leamer (1984)], and one may feel that the cost of collecting the additional data would be too large in comparison to the benefit derived from the fact of possibly producing somewhat more accurate estimators.

In line with the above considerations, one of the purposes of the present paper is to insist on the perverse effects of the presence of errors of measurement in the independent variables on statistical inference from standard linear regression models. Such errors in the variables lead to inconsistency of the OLS estimators of the regression parameters, to larger mean-squared errors and probably, most importantly, to larger than intended sizes of type I errors of Student tests.

Inconsistency. The case of the simple regression model is well known. If the single regressor is measured with error, the probability limit of the OLS estimator of its coefficient has always the same sign as the true coefficient itself and is smaller in absolute value. Moreover, the OLS estimator remains consistent when the true coefficient is equal to zero. The situation, however, is not as neat when the model includes more than one regressor. For example, in the case of two correlated regressors, the OLS estimator of the coefficient associated with one of the regressor will generally remain inconsistent even when its true value is equal to zero, if the 
coefficient associated with the other regressor is different from zero and there are errors of measurement in at least one of the explanatory variables. Furthermore, with similar measurement errors, the gaps between the true coefficients and the probability limits of their OLS estimators may be considerably larger when the true explanatory variables are strongly correlated.2

Mean-squared error.3 Although OLS estimators have relatively small variances in regression models with errors in the independent variables, these estimators may have larger mean-squared errors than alternative consistent estimators (with smaller finite sample biases) when a) the variances of the errors of measurement are relatively large since in this case, the biases of the OLS estimators will be important, b) the sample size is relatively large since then, the variances of all estimators are small and the relative importance of the squared biases of the OLS estimators is greater. Situations of these types will be illustrated below, in the results of the Monte Carlo experiments.

Type I error. One of the most perverse effects of ignoring the presence of errors in the independent variables, concerns the highly misleading determination of the confidence intervals of the regression parameters and of the sizes of the type I errors when testing hypotheses. Because OLS estimators have relatively small variances but are biased, intended $95 \%$ confidence intervals may in practice turn out to be almost $0 \%$ intervals,

2 This is illustrated in Dagenais and Dagenais (1994).

3 Note that OLS estimators may not have moments in finite samples when there are errors in the explanatory variables, unless it is implicitly assumed that the density function of the measurement errors is such that it excludes the sample points which could prevent the relevant integrals from having finite values. 
even when the errors of measurement are not exceedingly large, as will be illustrated below! Similarly, Student t-tests using the critical values corresponding normally to $5 \%$ type I errors, may in fact correspond to tests with type I errors of size equal to almost $100 \%$ ! This may have dramatic consequences since one may be induced to reject a null hypothesis when this hypothesis is true, with a probability close to $100 \%$ ! Contrary to the traditional case, increasing the sample size does not improve the matter but worsens it, since the importance of the bias relative to that of the standard error of the parameter estimator increases.

Now, even if one is convinced that it is important to take account of errors in the variables of one's data set, one is still left with the problem that it is not easy to identify appropriate instrumental variables and that these variables may often not be readily available [Pal (1980)]. An alternative to the instrumental variable approach that has received little attention in the literature, is to use consistent estimators based on sample moments of higher order than two. Pal (1980) presents a number of such estimators which remain consistent under quite reasonable hypotheses. Pal proposes several estimators based on third-order sample moments for the simple regression model. He mentions that one of these estimators had already been suggested by Durbin (1954), another one by Drion (1951) and a third one by Geary (1942). In particular, Durbin's estimator has the property of also being unbiased when there are no errors in the variables. It also extends readily to the case of models containing more than one regressor. Consistent estimators based on even higher sample moments also exist. For the case of a single regressor, estimators based on fourth-order moments have been proposed by Geary (1942) as well as Pal (1980). Although these estimators have not been generalized for multiple regression models, we will see below that it is possible to do so. 
However, it has long been recognized that regression estimators based on higher moments are notably more erratic than the corresponding least squares estimators [Kendall and Stuart (1963), p. 56; Malinvaud (1978)]. This most probably explains why such estimators have almost never been used in actual applications. The main purpose of this paper is therefore to suggest new higher moment (HM) estimators which in the examples considered in our numerical applications turn out to have considerably smaller standard errors than the HM estimators previously suggested.4

In our numerical illustrations section based on Monte Carlo experiments, it will be shown that in survey data analyses with several hundred observations, even when the variance of the errors of measurement for a given variable is not very large (say $10 \%$ of the variance of the variable), usual t tests based on OLS estimators performed at the $5 \%$ intended significance level may, in fact, have a probability of type I error of more than $85 \%$. If the measurement errors are larger, the same problem may be encountered for much smaller samples. In contrast, tests based on our HM estimators have type I error probabilities of approximately the right size in all situations. In terms of root mean-squared error, our experiments suggest that in a number of situations, the OLS estimator beats our HM estimators in small samples, but that in larger samples, the HM estimators are superior, even when the variances of the measurement errors are small. Even in samples that are not very large, however, if the measurement errors have relatively large variances (e.g., $25 \%$ of the variances of the affected variables), our findings indicate that the HM estimators may still, turn out to have smaller mean-squared errors than the OLS estimator.

4 For an alternative approach to obtain consistent regression estimators applicable to a variety of errors-in-variables models with panel data, see Griliches and Hausman (1986). 
It is also possible to use our suggested estimators to perform tests of errors in the variables. We shall indeed propose a simple procedure below. It appears from our experiments that the proposed test may be useful when it really matters. This is the case in large samples, even if the errors are relatively small and if the multiple correlation coefficient is low : a situation often encountered in microeconomic analyses based on survey data. It is also the case in smaller samples, when the multiple correlation coefficient is high and the measurement errors are relatively important : a typical situation in macroeconomic studies.

\section{THE SUGGESTED ESTIMATORS}

Let us assume that we have the following regression model :

$$
\mathrm{Y}=\alpha l_{\mathrm{N}}+\tilde{\mathrm{X}} \beta+\mathrm{u}
$$

where $\tilde{\mathrm{X}}$ is a $\mathrm{N} \times \mathrm{K}$ matrix of stochastic exogenous variables measured without error and such that $\mathrm{E}\left(\tilde{\mathrm{X}}^{\prime} \tilde{\mathrm{X}} / \mathrm{N}\right)=\mathrm{P} 1 \mathrm{i} \mathrm{m}\left(\tilde{\mathrm{X}}^{\prime} \tilde{\mathrm{X}} / \mathrm{N}\right)=\mathrm{Q}$, where $\mathrm{Q}$ is a finite nonsingular $\mathrm{N} \rightarrow \infty$

matrix. The $\mathrm{N} \times 1$ vector $\mathrm{u}$ is a vector of normal residual errors, independent of the variables contained in $\tilde{X}$, with covariance matrix $\sigma^{2} I_{N}, Y$ is the $N \times 1$ vector of observations of the dependent variable and $\mathrm{I}_{\mathrm{N}}$ is the identity matrix of order $\mathrm{N}$. The $\mathrm{K} \times 1$ vector $\beta$ and $\sigma^{2}$ are unknown parameters. The scalar $\alpha$ is also an unknown parameter.

We also assume that $\widetilde{X}$ is unobservable and that the matrix $\mathrm{X}$ is observed instead, where

$$
\mathrm{X}=\widetilde{\mathrm{X}}+\mathrm{V}
$$


and $\mathrm{V}$ is a $\mathrm{N} \times \mathrm{K}$ matrix of normally distributed errors in the variables. It is further assumed that $\mathrm{V}$ is uncorrelated with $\mathrm{u}$ and that

$$
\operatorname{Var}[\operatorname{Vec}(\mathrm{V})]=\sum \otimes \mathrm{I}_{\mathrm{N}},
$$

where $\operatorname{Var}[\cdot]$ stands for the covariance matrix and $\sum$ is a $\mathrm{K} \times \mathrm{K}$ symmetric positive definite matrix. This last assumption implies that the errors in the variables are independent between observations but not between variables. It also implies that for a given variable, the errors of measurement are homoskedastic.

The above model may be rewritten as :

$$
\mathrm{Y}=\alpha l_{\mathrm{N}}+\mathrm{X} \beta+\mathrm{u}-\mathrm{V} \beta=\alpha l_{\mathrm{N}}+\mathrm{X} \beta+\eta
$$

The HM estimator $(\widetilde{\theta})$ of $\theta=\left(\alpha, \beta^{\prime}\right)^{\prime}$ is derived from the following orthogonality conditions :

$$
\underset{\mathrm{N} \rightarrow \infty}{\mathrm{E}}\left(\mathrm{Z}^{\prime} \eta / \sqrt{\mathrm{N}}\right)=0
$$

where

$$
\begin{aligned}
\mathrm{Z}= & \left(l_{\mathrm{N}}, \mathrm{z}_{1}, \ldots, \mathrm{z}_{7}\right), \\
\mathrm{z}_{1} & =\mathrm{x} * \mathrm{x}, \mathrm{z}_{2}=\mathrm{x} * \mathrm{y}, \mathrm{z}_{3}=\mathrm{y} * \mathrm{y}, \\
\mathrm{z}_{4} & =\mathrm{x} * \mathrm{x} * \mathrm{x}-3 \mathrm{x}\left[\mathrm{E}\left(\mathrm{x}^{\prime} \mathrm{x} / \mathrm{N}\right) * \mathrm{I}_{\mathrm{K}}\right], \\
\mathrm{z}_{5} & =\mathrm{x} * \mathrm{x} * \mathrm{y}-2 \mathrm{x}\left[\mathrm{E}\left(\mathrm{x}^{\prime} \mathrm{y} / \mathrm{N}\right) * \mathrm{I}_{\mathrm{K}}\right] \\
& -\mathrm{y}\left\{\imath_{\mathrm{K}}^{\prime}\left[\mathrm{E}\left(\mathrm{x}^{\prime} \mathrm{x} / \mathrm{N}\right) * \mathrm{I}_{\mathrm{K}}\right]\right\} \\
\mathrm{z}_{6}= & \mathrm{x} * \mathrm{y} * \mathrm{y}-\mathrm{x}\left[\mathrm{E}\left(\mathrm{y}^{\prime} \mathrm{y} / \mathrm{N}\right)\right]-2 \mathrm{y}\left[\mathrm{E}\left(\mathrm{y}^{\prime} \mathrm{x} / \mathrm{N}\right)\right], \\
\mathrm{z}_{7}= & \mathrm{y} * \mathrm{y} * \mathrm{y}-3 \mathrm{y}\left[\mathrm{E}\left(\mathrm{y}^{\prime} \mathrm{y} / \mathrm{N}\right)\right],
\end{aligned}
$$


where the symbol * designates the Hadamard element by element matrix multiplication operator and, as mentioned earlier, $\mathrm{x}$ and $\mathrm{y}$ correspond to $\mathrm{X}$ and $\mathrm{Y}$ with the variables expressed in mean deviation form.5

The HM estimator is in fact an instrumental variable (IV) estimator, with $\mathrm{Z}$ as the matrix of instrumental variables. Note that besides being uncorrelated with the regression errors, the IV variables must also be correlated with the regressors. For this reason, a condition for $\widetilde{\theta}$ to be a consistent estimator is that the joint distribution of the variables contained in $\tilde{\mathrm{X}}$ is not multivariate normal [Reiersol (1950), Pal (1980)]. Because traditional IV or GMM (general method of moments) estimators [Hansen (1982)] that could be derived from the orthogonality conditions shown in equation (5) may not have moments in finite sample, we propose6 to use Fuller's modified IV estimator that possesses finite moments and improved small sample properties [Fuller (1987)] :

$$
\widetilde{\theta}=\left[\left(l_{\mathrm{N}}, \hat{\mathrm{X}}\right)^{\prime}\left(l_{\mathrm{N}}, \hat{\mathrm{X}}\right)-(\tilde{v}-\gamma) \mathrm{S}_{22}\right]^{-1}\left[\left(v_{\mathrm{N}}, \hat{\mathrm{X}}\right)^{\prime} \hat{\mathrm{Y}}-(\tilde{v}-\gamma) \mathrm{S}_{21}\right]
$$

where $\gamma$ is a constant term that we set equal to 1 , following Fuller's (1987, p 154) suggestion. Furthermore, $\hat{\mathrm{X}}, \hat{\mathrm{Y}}, \mathrm{S}_{22}, \mathrm{~S}_{21}$ and $\tilde{v}$ are defined as follows :

$$
(\hat{\mathrm{Y}}, \hat{\mathrm{X}})=\mathrm{Z}\left(\mathrm{Z}^{\prime} \mathrm{Z}\right)^{-1} \mathrm{Z}^{\prime}(\mathrm{Y}, \mathrm{X})
$$

$\tilde{v}$ is the smallest root of

5 The proof that $E\left(Z^{\prime} \eta / \sqrt{N}\right)=0$ is given in appendix A. Note that since $x$ is a matrix and $y$ is a vector, $\mathrm{x} * \mathrm{y}=\left(\mathrm{x}_{1} * \mathrm{y}, \ldots, \mathrm{x}_{\mathrm{K}} * \mathrm{y}\right)$, where $\mathrm{x}_{\mathrm{j}}(\mathrm{j}=1, \ldots, \mathrm{K})$ is the $\mathrm{j}$ 'th column of $\mathrm{x}$.

6 Following, in this matter, the advice of one of the referees. 


$$
\left|\left(\hat{\mathrm{Y}}, \iota_{\mathrm{N}}, \hat{\mathrm{X}}\right)^{\prime}\left(\hat{\mathrm{Y}}, \iota_{\mathrm{N}}, \hat{\mathrm{X}}\right)-v \mathrm{~S}\right|=0
$$

where $S$ is a $(K+2) x(K+2)$ matrix :

$$
\mathrm{S}=\left[\left(\mathrm{Y}, \iota_{\mathrm{N}}, \mathrm{X}\right)^{\prime}\left(\mathrm{Y}, \iota_{\mathrm{N}}, \mathrm{X}\right)-\left(\mathrm{Y}, \iota_{\mathrm{N}}, \mathrm{X}\right)^{\prime} \mathrm{Z}\left(\mathrm{Z}^{\prime} \mathrm{Z}\right)^{-1} \mathrm{Z}^{\prime}\left(\mathrm{Y}, \iota_{\mathrm{N}}, \mathrm{X}\right)\right] /(\mathrm{N}-\mathrm{q})
$$

and $q$ corresponds to the number of columns in $\mathrm{Z}$, namely : $5 \mathrm{~K}+3$.

The vector $S_{21}$ is a submatrix containing rows 2 to $\mathrm{K}+2$ and column 1 of $\mathrm{S}$; and $\mathrm{S}_{22}$ is a square symmetric submatrix containing rows 2 to $\mathrm{K}+2$ and columns 2 to $\mathrm{K}+2$ of $\mathrm{S}$. Note that since the dummy variable $l_{\mathrm{N}}$ is measured without error, the second row and the second column of $S$ are vectors of zeros [Fuller (1987), p. 150]. A feasible estimator is obtained by replacing $\underset{N \rightarrow \infty}{E} x^{\prime} x / N, \underset{N \rightarrow \infty}{E} x^{\prime} y / N$ and $\underset{N \rightarrow \infty}{E} y^{\prime} y / N$ in Z, by x'x / N, x'y / N and y'y / N.

As shown in Appendix B, the asymptotic covariance matrix (V) of $\sqrt{\mathrm{N}}(\widetilde{\theta}-\theta)$ can be estimated by :

$$
\hat{\mathrm{V}}=\mathrm{A}^{-1} \mathrm{~B}\left[\sum_{\mathrm{i}=1}^{\mathrm{N}} \mathrm{Z}_{\mathrm{i}}^{\prime} \mathrm{Z}_{\mathrm{i}} \tilde{\eta}_{\mathrm{i}}^{2} / \mathrm{N}\right] \mathrm{B}^{\prime} \mathrm{A}^{-1}
$$

where $\tilde{\eta}_{\mathrm{i}}=\mathrm{Y}_{\mathrm{i}}-\left(\iota_{\mathrm{N}}, \mathrm{X}_{\mathrm{i}}\right) \widetilde{\theta}$ and $\mathrm{Z}_{\mathrm{i}}, \mathrm{Y}_{\mathrm{i}}$ as well as $\mathrm{X}_{\mathrm{i}}$ correspond respectively to the $\mathrm{i}^{\prime}$ th rows of $\mathrm{Z}, \mathrm{Y}$ and $\mathrm{X}$. Now,

$$
\mathrm{A}=\left[\left(l_{\mathrm{N}}, \hat{\mathrm{X}}\right)^{\prime}\left(v_{\mathrm{N}}, \hat{\mathrm{X}}\right)-(\tilde{v}-\gamma) \mathrm{S}_{22}\right] / \mathrm{N}
$$

and

$$
\mathrm{B}=\left(l_{\mathrm{N}}, \hat{\mathrm{X}}\right)^{\prime} \mathrm{Z}\left(\mathrm{Z}^{\prime} \mathrm{Z} / \mathrm{N}\right)^{-1} / \mathrm{N}
$$


We also consider, in the numerical illustrations of section 5, below, the simpler estimator $\theta^{*}$ obtained by replacing $\mathrm{Z}$ by $\widetilde{Z}=\left(l_{N}, z_{1}, z_{4}\right)$, because we have noted that the results that we obtain for the RMSE's with this estimator are even slightly better than those obtained with $\widetilde{\theta}$.

\section{TESTING FOR THE PRESENCE OF ERRORS IN THE VARIABLES}

The null hypothesis $\left(\mathrm{H}_{0}\right)$ that there are no errors in the variables can be tested by applying a Durbin-Wu-Hausman type test [Durbin (1954), Wu (1973), Hausman (1978)]. This asymptotic test is most easily performed by the following procedure [Davidson and MacKinnon (1993)].

1) Run the following augmented regression by OLS :

$$
\mathrm{Y}=\alpha_{l}+\mathrm{X} \beta+\hat{\mathrm{w}} \psi+\varepsilon
$$

where $\hat{\mathrm{w}}=\mathrm{X}-\hat{\mathrm{X}}, \psi$ is a vector of parameters and $\varepsilon$ is the vector of the regression errors.

2) Test $\psi=0$, using the usual $F$ test.

If there are no errors in the variables, $\mathrm{X}=\tilde{\mathrm{X}}$ and $\mathrm{Y}=\alpha_{l_{\mathrm{N}}}+\mathrm{X} \beta+\mathrm{u}$. Therefore, under $\mathrm{H}_{0}, \varepsilon=\mathrm{u}$ and $\psi=0$.

\section{POSSIBLE EXTENSIONS}

Several possible extensions of the HM estimators described in section 2 come to mind. For example, if one is not willing to make the assumption that the nature of the joint density function of the errors in the variables is known, but only that it is 
symmetric, $\mathrm{z}_{4}$ should be removed from the definition of $\mathrm{Z}$ in equation (6), to preserve the consistency of the estimator. Similarly, if one assumes that the density of the regression errors is unknown but symmetric, $z_{7}$ should be removed for the same reason. 7

One could also devise a pretest estimator by adopting the following procedure : 1) test for the presence of errors in the variables, 2) if $\mathrm{H}_{0}$ cannot be rejected, use the OLS estimator, otherwise use the HM estimator.

One could introduce on the right-hand side of equation (6), which defines the $\mathrm{Z}$ matrix, other "instrumental variables" based on higher sample moments than the third and fourth, or extraneous instrumental variables that are available. If some variables are assumed to be observed without error, they could be introduced directly into the $\mathrm{Z}$ matrix, as was done for the $l_{\mathrm{N}}$ vector. In the same vein, one could make separate EV tests for each of the $\mathrm{X}$ variables, that is, make separate tests for each of the elements

7 If one assumes that the u's have a given known symmetric density other than the normal, $\mathrm{z}_{7}$ could be retained, but the factor 3 appearing in the second term of the right-hand side of equation (11), which defines $z_{7}$, should then be replaced by $K_{1}$, where $K_{1}$ is a known quantity equal to the ratio of the fourth centered moment of the density of the u's divided by the square of its second centered moment. Similarly, if one assumes that the joint density of the V's is a given joint symmetric density other than the normal and that this density has the following property : $\mu(\mathrm{i}, \mathrm{j})=\mathrm{K}_{2} \mu(2,0) \mu(2-\mathrm{j}, \mathrm{j})$, for $(\mathrm{i}, \mathrm{j})=(4,0)$ or $(\mathrm{i}, \mathrm{j})=(3,1)$, where $\mu(\mathrm{i}, \mathrm{j})$ designates the centered bivariate cross-moment of order $\mathrm{i}, \mathrm{j}$, the factor 3 appearing in the second term of the right-hand side of equation (8), which defines $z_{4}$, should be replaced by $\mathrm{K}_{2}$. Note that if the values of $\mathrm{K}_{1}$ and $\mathrm{K}_{2}$ are unknown, they could be considered as extra parameters to be estimated. (In the case of the normal distribution, $\mathrm{K}_{2}=3 \quad$ [Kendall and Stuart (1963), p. 91].) 
of $\psi$ in equation (19) and "instrument" only the variables for which the null hypothesis is rejected.

Some of the assumptions underlying the model presented in section 2 could also be relaxed. For example, if the V's are assumed to be heteroskedastic, our estimator $\widetilde{\theta}$ would remain consistent, provided the distribution of the variances of the V's is independent of the $\tilde{X}^{\prime}$ s, and provided $z_{4}$ is excluded from Z. Similarly, if the u's are assumed to be heteroskedastic, the estimators would remain consistent if the variances of the u's are distributed independently of the $\tilde{X}^{\prime}$, but $z_{7}$ would have to be removed from Z. If the V's or the u's are serially correlated, provided they are stationary and ergodic [White (1984)], our estimators would still be consistent. The asymptotic covariance matrix of the estimators would, however, be somewhat more complicated to evaluate.

\section{NUMERICAL ILLUSTRATIONS}

\section{A) Description of data and experiment setup}

The numerical experiments reported below concern essentially the performance of the $\widetilde{\theta}$ and $\theta^{*}$ estimators relative to the OLS estimator $\hat{\theta}$.

The performance criteria generally used in such studies are the bias and the root mean-squared error (RMSE). 8 We also use the discrepancy between the intended and true sizes of the type I errors for tests of null hypotheses, because this criterion appears to be particularly important in the present context for reasons given previously.

8 For the OLS estimator, see our remark in footnote 3. 
The data used for the Monte Carlo experiments reported below are drawn from the 1986 survey of Consumer Finances of Statistics Canada (1988). A simple model relating total annual household consumption to the following variables was set up :

$\widetilde{X}_{1}$ : total annual income of the household;

$\widetilde{X}_{2}:$ age of the head of the household;

$\tilde{X}_{3}$ : number of person-weeks constituting the household during the year.

In order to preserve a certain homogeneity of the sample, we retained only the observations for which the total income of the household ranged between $\$ 25,000$ and $\$ 55,000$. The total sample available included 4,400 observations. We first ran a regression using observed consumption and observed income, age and person-weeks. Then we scaled the explanatory variables so that each of the estimated coefficients became equal to one. We then used the independent variables thus scaled with $\theta=(1,1,1,1)^{\prime}$ to generate the consumption vectors used in our Monte Carlo experiments.9

More precisely, the model used was the following :

$$
Y_{i}=X_{0 i}+\tilde{X}_{1 i}+\widetilde{X}_{2 i}+\widetilde{X}_{3 i}+u_{i}(i=1, \ldots, N)
$$

where $\mathrm{X}_{0 \mathrm{i}}=1$ for every $\mathrm{i}, \mathrm{u}_{\mathrm{i}}$ is the normal regression error term, $\mathrm{Y}_{\mathrm{i}}$ is household consumption and $\mathrm{N}$ is the sample size. All data are expressed in logarithms. Then normal random errors in the variables were added to the $\tilde{X}_{1 i}$ variable to obtain $X_{1 i}=\tilde{X}_{1 i}+V_{1 i}$. Since no errors were added to $\tilde{X}_{2 i}$ and $\tilde{X}_{3 i}$, we have $X_{2 i}=\tilde{X}_{2 i}$ and $\mathrm{X}_{3 \mathrm{i}}=\widetilde{\mathrm{X}}_{3 \mathrm{i}}$

\footnotetext{
9 Setting all elements of $\theta$ to 1 simplifies the analysis of the tables of results shown below.
} 
Because the squared multiple correlation coefficient $\left(\mathrm{R}^{2}\right)$ that was obtained when we regressed the actual data was equal to approximately 0.40 , we set, in all experiments reported in the next subsection, the variance of $u_{i}$ so as to obtain a theoretical squared multiple correlation coefficient of 0.40 when using our 4,400 available observations. Similarly, since studies made on the accuracy of reported earnings data [Rodgers, Brown and Duncan (1993); Bound and Krueger (1991)] suggest that the ratio $(\lambda)$ of the variance of measurement errors to the variance of declared individual earnings expressed in logarithms is more than 0.2 for men, and since measurement errors for total household income, which includes nonlabor income, is believed to be greater than for earnings [Altonji and Siow (1987); Radner (1982)], we set, in our first experiment, the variance of $\mathrm{V}_{1}$ so as to obtain a value of $\lambda_{1}=\left(\sigma_{v_{1}}^{2} / \sigma_{\tilde{x}_{1}}^{2}\right)$ equal to 0.3.10 Finally, in this same experiment, we set $\mathrm{N}=2,000$, which is not a very large sample size, according to present standards, for household surveys. 11

10 Rodgers, Brown and Duncan (1993) also suggest that in the case of earnings, the measurement errors are not independent of the true values, but they are negatively correlated ("mean reverting"). It is not known, however, if this is also the case for total income. The possibility that measurement errors are correlated with the true values is not considered in the present paper. Further research is needed to analyze this case.

11 Note that in these illustrative experiments, we have used the instrumental variables defined by equations (7)-(11) for all three regressors, even if only the income variable $\tilde{\mathrm{X}}_{1}$ contained errors of measurement. We could alternatively have assumed that the analyst knows that $\tilde{\mathrm{X}}_{2}$ and $\tilde{\mathrm{X}}_{3}$ are measured without error. In this case, $\tilde{X}_{2}$ and $\tilde{X}_{3}$ could have been introduced directly into the IV matrices, as suggested in Section 4 and illustrated in the application reported in Section 6. 
We then made a second experiment where the value of $\lambda_{1}$ was reduced markedly to 0.1 , and a third experiment where, in turn, $\mathrm{N}$ was reduced to 700 . We also made a fourth experiment where we set $\beta_{3}=0$ instead of 1 and verified the size of the probability of rejecting this (true) null hypothesis, using the different estimators. Finally, since the collinearity between our independent variables is very small, we made a fifth experiment analogous to the fourth, in which $\widetilde{X}_{3}$ was transformed so as to be much more highly correlated with $\widetilde{\mathrm{X}}_{1}$. Prior to transformation, the correlation coefficient between $\widetilde{X}_{1}$ and $\widetilde{X}_{3}$ was 0.15 and after transformation it was equal to 0.5 .

Before reporting our results, we would like to insist on the fact that the nazee model presented here is used only for illustration purposes. It is clearly inadequate for analyzing household consumption. It could be argued, on the one hand, that consumption may be more closely related to perceived income than to actual income and that declared income may be closer to perceived income than to true income. This would suggest that the value of $\lambda_{1}$ may be smaller than that used in all our experiments, except possibly in the second experiment. On the other hand, if consumption depends on "permanent" income, the discrepancy between this notion of income and declared annual income might correspond to a much larger value of $\lambda_{1}$. This would most likely still be true even if $\tilde{X}_{1}$ were replaced by better approximations to "permanent" income than the declared annual income.12 Finally, it must be pointed out that present consumption might also be influenced by past savings [Avery (1991)] or accumulated wealth [Avery, Elliehausen and Kennickel (1988)], and these variables are likely to contain even much larger errors in the variables than income.

12 See Jeong and Maddala (1991) about measurement errors in expectations data. 


\section{B) The results of the Monte Carlo experiments}

We report, in Table 1, section A, from our first experiment,13 the root mean-squared errors for the $\hat{\theta}, \theta^{*}$ and $\widetilde{\theta}$ estimators. In addition, similar results are given for the HM estimators based only on $z_{1}$ [Durbin (1954)] or $z_{4}[$ Pal (1980)] designated respectively as $\theta_{\mathrm{d}}$ and $\theta_{\mathrm{p}}$. These results clearly illustrate why HM estimators previously proposed in the literature were almost never used in practice. For example, the averages of their RMSE's for all four parameters are approximately from three to five times larger than the average RMSE for the elements of $\theta^{*}$. They are even larger than the average RMSE associated with $\hat{\theta}$, which is itself $70 \%$ larger

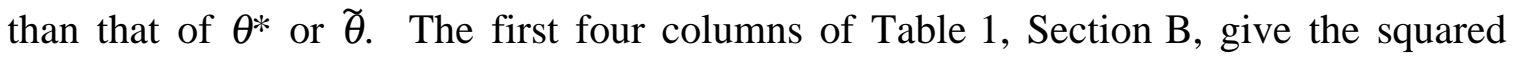
multiple correlation coefficients of the regressions of the true explanatory variables on the set of instruments used for each HM estimator. The poor performance of $\theta_{d}$ and $\theta_{p}$ may be explained by the fact that the $R^{2}$ s associated with some of the $\tilde{X}$ variables are quite low.

One notices also that, on average, the RMSE's associated with the $\widetilde{\theta}$ estimator are slightly larger than those associated with $\theta^{*}$, despite the fact that the latter uses only a subset of the instruments. Asymptotically, RMSE's of $\widetilde{\theta}$ could not be smaller than those of $\theta^{*}$. In finite samples, however, adding instruments that are weakly correlated with the true $\widetilde{X}^{\prime}$ s or that are strongly correlated with the subset of instruments already used, may affect the performance of the estimator adversely [Bowden (1984, p. 38)]. In the case at hand, the additional instruments used for $\tilde{\theta}$ are not strongly correlated with those already used for $\theta^{*}$, but their correlations with the true regressors are weaker than those of the instruments used for $\theta^{*}$. Indeed, on he one hand, the $\mathrm{R}^{2 \text { s }}$ of the

13 All Monte Carlo experiments reported below are based on 1,000 replications. This number of replications appeared to be largely sufficient to assure a two-digit accuracy (based on $95 \%$ confidence intervals) for most of the results presented in the tables. 
regressions of each of the eleven variables contained in $\bar{Z}$, where $\bar{Z}=\left(z_{2}, z_{3}, z_{5}, z_{6}, z_{7}\right)$, on $\widetilde{Z}$ range from 0.030 to 0.350 , with an average of 0.105 . On the other hand, the $R^{2}$ s of the regressions of the true $\widetilde{X}^{\prime}$ s on the variables contained in $\widetilde{Z}$ are notably larger than those of the corresponding regressions on $\left(l_{N}, \bar{Z}\right)$, as can be verified by comparing columns (5) and (3) in Table 1, B. Finally, if the residuals of the regressions of each of the true $\widetilde{X}^{\prime}$ s on $\widetilde{Z}$ are in turn regressed on $\bar{Z}$, the $R^{2 \text { s }}$ are very low, namely $0.036,0.051$ and 0.008 for $\widetilde{X}_{1}, \widetilde{X}_{2}$, and $\widetilde{X}_{3}$ respectively, thus confirming that once the instruments contained in $\tilde{Z}$ have been introduced, the marginal contribution of the instruments contained in $\bar{Z}$ is negligible.14

Table 2 also reports the results of experiment 1. It gives the biases and sizes of type I errors associated with each parameter for $\hat{\theta}, \theta^{*}$ and $\widetilde{\theta}$. The sizes of the type I errors were measured by calculating the percentage of replications for which the true value of the parameter was not included in the computed $95 \%$ confidence interval. One notices that the bias of the OLS estimator of $\beta_{1}$ is close to what it would be in the simple regression case, namely : $0.3 / 1.3=0.231$. This is not surprising since in this example, the correlation between $\widetilde{\mathrm{X}}_{1}$ and $\widetilde{\mathrm{X}}_{2}$ as well as $\widetilde{\mathrm{X}}_{3}$ is very low. What is most disturbing, however, is that the computed sizes of the type I errors for the OLS estimators of $\alpha$ and $\beta_{1}$ are equal to $100 \%$ ! The sizes of the type I errors for all the elements of our HM estimators are, on the contrary, much closer to the intended $5 \%$ level. Finally, the powers of the EV tests based on $\widetilde{Z}$ and $\mathrm{Z}$ are both quite high.

Table 3 gives the results of the second experiment. In this experiment, the relative importance of the measurement errors in $\widetilde{X}_{1}$ was reduced notably, since $\lambda_{1}$ was

14 Note that all variables contained in $\bar{Z}$ involve $\mathrm{Y}$ and in our experiments, the $\mathrm{R}^{2}$ between the $\mathrm{Y}$ 's and the $\tilde{\mathrm{X}}_{\text {'s }}$ is rather low, namely 0.4 . This could explain why the $\mathrm{z}$ variables contained in $\overline{\mathrm{Z}}$ are less correlated with the true regressors than those contained in $\widetilde{Z}$. 
set to 0.1. Even then, the performance of our HM estimators is comparable to that of the OLS estimator in terms of the average values of the root mean-squared errors. However, the OLS estimator behaves rather poorly, as far as the sizes of type I errors for $\alpha$ and $\beta_{1}$ are considered. As could be anticipated, the power of the tests has decreased notably. Note that these tests are based on $5 \%$ critical values. In the case of the Durbin-Watson autocorrelation test, Fomby and Guilkey (1978) have argued that $50 \%$ critical values should be used instead of the traditional $5 \%$. A similar strategy would clearly increase the power of our tests.

Table 4 presents the results of experiment 3. The purpose of this experiment was to verify whether our HM estimators could still outperform $\hat{\theta}$ with smaller sample sizes. One can see that even for $\mathrm{N}=700$, the $\mathrm{HM}$ estimators are still preferable to $\hat{\theta}$, especially in terms of the sizes of the type I errors for $\alpha$ and $\beta_{1}$. Note also that in all three experiments, the EV tests based on $\mathrm{Z}$ were more powerful than those based on $\widetilde{Z}$. This is particularly the case for experiment 3 in which the sample size was reduced.

A fourth experiment was made under the same conditions as experiment 1 , but the value of $\beta_{3}$ was set equal to zero. Despite the facts that 1) in simple regression models asymptotic biases disappear when the coefficient is equal to zero, 2) $\widetilde{X}_{3}$ itself did not contain errors of measurement but only $\tilde{X}_{1}$ was measured with errors and, finally, 3) $\tilde{X}_{1}$ and $\tilde{X}_{3}$ were weakly correlated $\left(r_{13}=0.153\right)$, the bias of the OLS estimator of $\beta_{3}$ was non-negligeable (0.103) and the size of the type I error associated with the test that $\beta_{3}=0$ was rather large $(26.90 \%)$. This means that in more than $25 \%$ of the cases, the t-test based on an intended $95 \%$ confidence level would have led one to reject the true hypothesis that $\beta_{3}=0$. The other results pertaining to this experiment are similar to those of experiment one and are not reported here. If the correlation between $\widetilde{X}_{1}$ and $\widetilde{X}_{3}$ is raised to 0.5 , as was done in the last experiment, the bias of the OLS estimator of $\beta_{3}$ increases to 0.358 and the size of the type I error 
reaches $99 \%$ ! The average RMSE of $\hat{\theta}$ also deteriorates markedly, as can be verified from Table 5.15

\section{C) Summary of experimental findings}

The above Monte Carlo experiments, in combination with an extensive set of experiments made in the early phases of this research project on the performance of estimators similar to $\theta^{*}$ [Dagenais and Dagenais (1993)] in which errors of measurement were assumed to affect only one of the explanatory variables (say $\widetilde{X}_{1}$ ), suggest the following general conclusions.16

\section{Bias}

1) The value of the squared multiple correlation coefficient of the regression seems to have no effect on biases.

15 The results obtained in a previous version of the paper [Dagenais and Dagenais (1994)] in which more traditional IV estimators were used instead of Fuller's (1987) estimators, were similar to those reported here. In most cases, the RMSE's obtained with Fuller's estimators are slightly smaller than those obtained previously. The largest differences are found for experiment 5 (see Table 5) where the average RMSE's comparable to those of $\theta^{*}$ and $\widetilde{\theta}$ were 0.302 and 0.323 respectively, instead of 0.288 and 0.298 .

16 In the following paragraphs, we use expressions such as : "small" samples and "small" values of $\lambda$ or $\mathrm{R}^{2}$. Although it is difficult to be very precise in such matters, we would say that "small" samples refer roughly to samples smaller than 500 observations. "Small" values of $\lambda$ or $\mathrm{R}^{2}$ indicate values of $\lambda$ smaller than, say, 0.05 and values of $\mathrm{R}^{2}$ lower than 0.25 . In contrast, "large" samples are samples of more than 1,000 observations, "large" values of $\lambda$ are values greater than 0.25 and "large" $\mathrm{R}^{2 \text { s }}$ are $\mathrm{R}^{2}$ 's greater than 0.75 . 
2) The sample size has no effect on the biases of the elements of the OLS estimator.

3) The biases of the elements of our HM estimators are notably smaller than those of the corresponding elements of the OLS estimator, in small samples.

4) As the sample size grows, the biases of the elements of our HM estimators vanish progressively.

5) The biases of the elements of the OLS estimators increase with $\lambda_{1}$.

6) In small samples, the biases of the elements of the HM estimators are larger for greater values of $\lambda_{1}$. Furthermore, when $\lambda_{1}$ is larger, these biases do not vanish as rapidly, when the sample size grows.

7) When the independent variables are highly collinear, the bias of the OLS estimator of the parameter affecting a variable measured with error may be larger than it would be in the simple regression case. The OLS estimators of the coefficients of the correlated variables may also be strongly biased.

8) The size of the small-sample biases of our HM estimators do not seem to be much affected by the collinearity among the explanatory variables.

\section{Root mean-squared error}

1) For small values of $\mathrm{N}$, the RMSE's of the elements of the OLS estimator decrease as $\mathrm{R}^{2}$ or $\mathrm{N}$ increase. For larger values of $\mathrm{N}$, these RMSE's remain almost constant. This is easily explained by the fact that MSE equals squared bias plus 
variance and that the variance is $\mathrm{O}\left(\mathrm{N}^{-1}\right)$ while the bias is $\mathrm{O}(1)$. When $\mathrm{N}$ gets large, the MSE is essentially equal to the squared bias; hence, the factors affecting the variance no longer have an impact on the MSE.

2) For a given sample size, the RMSE's of the elements of the OLS and HM estimators increase with $\lambda_{1}$.

3) The RMSE's of the elements of the HM estimators are also strongly influenced by the value of $\mathrm{R}^{2}$ and $\mathrm{N}$. The RMSE's decrease as $\mathrm{R}^{2}$ or $\mathrm{N}$ increase. These results are clearly explained by the fact that the HM estimators have relatively small biases and, hence, the MSE's are merely influenced by the variances. Therefore, the MSE's decrease as the variances decrease.

4) For small values of $\lambda_{1}, R^{2}$ or $N$, the OLS estimator may outperform the HM estimators.

5) The HM estimators may outperform the OLS estimator for much smaller sample sizes when collinearity is high.

6) The simpler estimator $\theta^{*}$ may perform better than the $\widetilde{\theta}$ estimator when the marginal contribution of the additional instruments used for $\widetilde{\theta}$ to the multiple correlation of the true regressors with the set of instruments is negligible.17

17 In practical applications, the multiple correlation coefficients obtained by regressing each variable contained in $\bar{Z}$ on $\widetilde{Z}$ could be computed and also those obtained by regressing each observed $\mathrm{X}$ on $\overline{\mathrm{Z}}$. If the former coefficients are low and the latter are high, one could anticipate that $\widetilde{\theta}$ might outperform $\theta^{*}$. Otherwise, $\theta^{*}$ should probably be used. 
Size of type I error

1) The relative performance of our HM estimators is always superior to that of the OLS estimator, when there are errors in the variables.

2) In all cases examined, the importance of the type I error of the Student t-tests associated with our HM estimators was always relatively close to the desired $5 \%$ level.

3) The performance of the OLS estimator deteriorates as $\lambda_{1}, \mathrm{R}^{2}$ or $\mathrm{N}$ increase. It is very disappointing even, for example, for values of $\lambda_{1}$ as low as $5 \%$. As discussed earlier, this is explained by the fact that OLS estimators are biased but have relatively small variances.

4) For given values of $\lambda_{1}, \mathrm{R}^{2}$ and $\mathrm{N}$, the sizes of the type I errors of the OLS estimators increase when the data are more collinear.

EV tests

1) The power of the tests increases with $\lambda_{1}, \mathrm{R}^{2}$ and $\mathrm{N}$.

2) The tests have little power for small samples, unless $R^{2}$ and $\lambda_{1}$ are large.

3) When $\mathrm{R}^{2}$ is low, the tests do not have much power for $\lambda_{1}$ smaller than $10 \%$, even in very large samples. Even for larger values of $\lambda_{1}$, the power remains fairly low in large samples, when $\mathrm{R}^{2}$ is small.

4) The performance of the tests improves significantly when $R^{2}$ increases. 
5) The EV tests are more powerful when the other explanatory variables are strongly correlated with the variables affected by measurement errors.

As mentionned in Section 2, our suggested approach applies when the joint distribution of $\widetilde{X}$ is non-normal.18 Experiments similar to experiment 1 made with a single regressor suggest that if its distribution is relatively close to the normal, such as [Johnson and Kotz (1970a) and (1970b)] the Student t-distribution, the $\chi^{2}$ with more than 100 degrees of freedom or the lognormal (where $\widetilde{X}$ is defined as $\widetilde{X}=\mathrm{e}^{\mathrm{u} / \delta}$, $\mathrm{u}$ is $\mathrm{N}(0,1)$ and $\delta>0)$ with $\delta>10$, the OLS estimator will outperform the HM estimators, in terms of RMSE's. The size of the Type 1 errors associated with the standard Student tests remains, however, considerably underestimated for the OLS estimators.

\section{AN ILLUSTRATIVE APPLICATION}

As illustrated above, our suggested HM estimators are likely to perform better than the OLS estimator in microeconomic analyses based on survey data where the sample comprises several hundred observations, even if the measurement errors are relatively small. Where analyses are based on smaller samples, only in situations involving more important measurement errors will our HM estimators exhibit a superior performance, in terms of root mean-squared errors. This is likely to be the case, however, in macroeconomic applications, since errors of measurement are known to be important in aggregate data [Morgenstern (1961); Dagenais (1992)]. This is illustrated below by applying our EV tests to the data used by Mankiw, Romer and Weil (1992) to analyze economic growth. Mankiw, Romer and Weil (MRW) estimated a human

18 The measures of skewness and kurtosis [Theil (1971)] for the three $\tilde{X}$ variables in the experiments reported in Section 5, B were $(-0.1920,1.9704),(-0.1235,2.1833)$ and $(-0.6250$, 3.0027) respectively, instead of $(0,3)$ for the normal distribution. 
capital augmented Solow model and tested it with macroeconomic data of 98 countries, using OLS estimators. With the data shown in the appendix of the MRW paper, we have accurately reproduced in our Table 6, the results appearing in the upper part of Table 2 of MRW. Table 6, section A, also gives the p-values of our joint F-tests of errors in the variables. Both versions of the test yield very low p-values. Given that these tests do not appear to be very powerful in small samples unless the errors of measurement are very large, there is a very strong presumption that the data used by MRW contain errors of measurement. Student t-tests applied separately to the coefficients associated with each of the three variables suggest that the variable $\ln (\mathrm{n}+\mathrm{g}+\delta)$ may be particularly error-ridden. MRW note also that the Student $\mathrm{t}$-statistics based on their OLS estimates strongly support the prediction of the augmented model to the effect that the coefficients of the three variables sum to zero. In the case of our more robust $\theta^{*}$ estimator, the sum of the coefficient is negative and fairly large in absolute value. The associated t-statistic is also notably larger in absolute value and rather indicates that the null hypothesis should be rejected. When the results associated with $\widetilde{\theta}$ are considered, one notes that the estimate of the sum of the coefficients is also negative and larger in absolute value than that based on the OLS estimator. However, the standard error of the $\tilde{\theta}$ estimate is large and the $t-$ statistic is notably smaller than that associated with $\theta^{*} .19$

19 Note that, in this example, the computed asymptotic standard errors of all the $\theta^{*}$ estimators are smaller than those of their $\widetilde{\theta}$ counterparts, even if the latter are based on a larger set of instruments. When usual IV estimators are used, adding instruments reduces necessarily the computed asymptotic standard errors, as it was the case in the previous version of the paper already mentionned in footnote 15 [Dagenais and Dagenais (1994)]. When Fuller's estimators are used, however, this systematic result no larger holds. 
The fact that our EV tests indicate that errors in the variables appear to plague mainly the second variable $\ln (\mathrm{n}+\mathrm{g}+\delta)$ suggests that more reliable results might be obtained by "instrumenting" only the second variable. The corresponding results are shown in Table 6 , section B. To be more precise, in the case of $\widetilde{\theta}, \ln (\mathrm{I} / \mathrm{GDP})$ and $\ln ($ school) were retained as instruments for themselves, and the instruments selected for $\ln \left(\mathrm{n}+\mathrm{g}+\delta\right.$ ) corresponded to $\mathrm{z}_{3}, \mathrm{z}_{7}$ and the second columns of $\mathrm{z}_{1}, \mathrm{z}_{2}, \mathrm{z}_{4}, \mathrm{z}_{5}$ and $\mathrm{z}_{6}$. In the case of $\theta^{*}$, the instruments for $\ln (\mathrm{n}+\mathrm{g}+\delta)$ corresponded to the second columns of $\mathrm{z}_{1}$ and $\mathrm{z}_{4}$. The results of Table 6 , section $\mathrm{B}$, show high absolute values of the $\mathrm{t}-$ statistics for both the $\widetilde{\theta}$ and $\theta^{*}$ estimates of the sum of the coefficients.

In final analysis, the very clear indications of the presence of errors in the variables supplied by our EV tests, together with the results obtained concerning the sum of the coefficients using the suggested HM estimators, specially with the restricted set of instruments, cast very strong doubts on MRW's claim that their data strongly support the human capital augmented Solow model. 


\section{APPENDIX A \\ THE ORTHOGONALITY CONDITIONS OF EQUATION (5)}

To prove that $\underset{\mathrm{N} \rightarrow \infty}{\mathrm{E}}\left(\mathrm{Z}^{\prime} \eta / \sqrt{\mathrm{N}}\right)=0$, we have to demonstrate that $\underset{N \rightarrow \infty}{E}\left(l_{N}^{\prime} \eta / \sqrt{\mathrm{N}}\right)=0$ and that $\underset{\mathrm{N} \rightarrow \infty}{\mathrm{E}}\left(\mathrm{z}_{\mathrm{m}}^{\prime} \eta / \sqrt{\mathrm{N}}\right)=0$, for $\mathrm{m}=1, \ldots, 7$.

Given that $\mathrm{E}(\eta)=0, \underset{\mathrm{N} \rightarrow \infty}{\mathrm{E}}\left(l_{\mathrm{N}}^{\prime} \eta / \sqrt{\mathrm{N}}\right)$ is clearly equal to zero.

1) $\underset{\mathrm{N} \rightarrow \infty}{\mathrm{E}}\left(\mathrm{z}_{1}^{\prime} \eta / \sqrt{\mathrm{N}}\right)=0$.

A typical element of $\mathrm{E}\left(\mathrm{z}_{1}^{\prime} \eta / \sqrt{\mathrm{N}}\right)$ is $\mathrm{E}\left(\mathrm{z}_{1 \mathrm{j}}^{\prime} \eta / \sqrt{\mathrm{N}}\right)=\mathrm{E}\left(\sum \mathrm{x}_{\mathrm{ij}}^{2} \eta_{\mathrm{i}} / \sqrt{\mathrm{N}}\right)$ where $\mathrm{j}=1, \ldots, \mathrm{K}, \mathrm{z}_{1 \mathrm{j}}$ is the $\mathrm{j}^{\prime}$ th column of $\mathrm{z}_{1}, \mathrm{x}_{\mathrm{ij}}$ is the ij'th element of $\mathrm{x}$ and, to simplify notation, $\sum$ stands for $\sum_{i=1}^{N}$.

Now,

$$
\mathrm{E} \sum \mathrm{x}_{\mathrm{ij}}^{2} \eta_{\mathrm{i}} / \sqrt{\mathrm{N}}=(1 / \sqrt{\mathrm{N}}) \mathrm{E}\left[\sum\left(\tilde{\mathrm{x}}_{\mathrm{ij}}^{2} \eta_{\mathrm{i}}+\mathrm{v}_{\mathrm{ij}}^{2} \eta_{\mathrm{i}}+2 \tilde{\mathrm{x}}_{\mathrm{ij}} \mathrm{v}_{\mathrm{ij}} \eta_{\mathrm{i}}\right)\right]
$$

where $\tilde{\mathrm{x}}_{\mathrm{ij}}$ is the $\mathrm{ij}$ th element of $\tilde{\mathrm{x}}$ and $\tilde{\mathrm{x}}$ corresponds to $\tilde{\mathrm{X}}$ in mean deviation form. Similarly, $v_{i j}$ is the $i j$ th element of $v$ and $v$ corresponds to $\mathrm{V}$ in mean deviation form. Then,

$$
\begin{aligned}
& \mathrm{E} \sum \tilde{\mathrm{x}}_{\mathrm{ij}}^{2} \eta_{\mathrm{i}}=\mathrm{E}\left(\sum \tilde{\mathrm{x}}_{\mathrm{ij}}^{2}\right) \mathrm{E}\left(\eta_{\mathrm{i}}\right)=0, \\
& \mathrm{E} \sum\left(\mathrm{v}_{\mathrm{ij}}^{2} \eta_{\mathrm{i}}\right)=\sum \mathrm{E}\left[\mathrm{v}_{\mathrm{ij}}^{2} \mathrm{u}_{\mathrm{i}}-\mathrm{v}_{\mathrm{ij}}^{2} \mathrm{v}_{\mathrm{i}} \beta\right],
\end{aligned}
$$


where $V_{i}$ is the $i^{\prime}$ th row of $V$. Since $u$ is independent of $V$ and $E(u)=0, E\left(v_{i j}^{2} u_{i}\right)=0$. Similarly, $\mathrm{E}_{\mathrm{ij}}^{2} \mathrm{v}_{\mathrm{i}} \beta=0$ since the elements of $\mathrm{v}_{\mathrm{i}}$ are normally distributed and hence, all third order moments are equal to zero.

Finally,

$$
\mathrm{E} \sum \tilde{\mathrm{x}}_{\mathrm{ij}} \mathrm{v}_{\mathrm{ij}} \eta_{\mathrm{i}}=\mathrm{E}\left(\sum \tilde{\mathrm{x}}_{\mathrm{ij}}\right) \mathrm{E}\left(\mathrm{v}_{\mathrm{ij}} \eta_{\mathrm{i}}\right)=0
$$

since $\tilde{\mathrm{x}}_{\mathrm{ij}}$ is independent of $\mathrm{v}_{\mathrm{ij}}$ and $\eta_{\mathrm{i}}$ and $\mathrm{E}\left(\sum \tilde{\mathrm{x}}_{\mathrm{ij}}\right)=0$.

2) $\underset{\mathrm{N} \rightarrow \infty}{\mathrm{E}}\left(\mathrm{z}_{2}^{\prime} \eta / \sqrt{\mathrm{N}}\right)=0$.

A typical element of $\mathrm{E}\left(\mathrm{z}_{2}^{\prime} \eta / \sqrt{\mathrm{N}}\right)$ is $\mathrm{E}\left(\mathrm{z}_{2 \mathrm{j}}^{\prime} \eta / \sqrt{\mathrm{N}}\right)=(1 / \sqrt{\mathrm{N}}) \mathrm{E}\left[\sum\left(\mathrm{x}_{\mathrm{ij}} \mathrm{y}_{\mathrm{i}} \eta_{\mathrm{i}}\right)\right]$, for $\mathrm{j}=1, \ldots, \mathrm{K}$.

Now,

$$
\mathrm{E} \sum \mathrm{x}_{\mathrm{ij}} \mathrm{y}_{\mathrm{i}} \eta_{\mathrm{i}}=\mathrm{E} \sum\left(\tilde{\mathrm{x}}_{\mathrm{ij}} \mathrm{y}_{\mathrm{i}} \eta_{\mathrm{i}}+\mathrm{v}_{\mathrm{ij}} \mathrm{y}_{\mathrm{i}} \eta_{\mathrm{i}}\right)
$$

and

$$
\mathrm{E} \sum \tilde{\mathrm{x}}_{\mathrm{ij}} \mathrm{y}_{\mathrm{i}} \eta_{\mathrm{i}}=\mathrm{E} \sum\left[\tilde{\mathrm{x}}_{\mathrm{ij}}\left(\tilde{\mathrm{x}}_{\mathrm{i}} \beta+\mathrm{u}_{\mathrm{i}}-\overline{\mathrm{u}}\right) \eta_{\mathrm{i}}\right],
$$

where $\overline{\mathrm{u}}=\sum \mathrm{u}_{\mathrm{i}} / \mathrm{N}$.

$$
\begin{aligned}
\mathrm{E}\left(\sum \tilde{\mathrm{x}}_{\mathrm{ij}} \mathrm{y}_{\mathrm{i}} \eta_{\mathrm{i}}\right)= & \sum\left[\mathrm{E}\left[\tilde{\mathrm{x}}_{\mathrm{ij}} \tilde{\mathrm{x}}_{\mathrm{i}} \beta\right) \mathrm{E}\left(\eta_{\mathrm{i}}\right)\right]+\sum \mathrm{E}\left(\mathrm{u}_{\mathrm{i}} \eta_{\mathrm{i}}\right) \mathrm{E}\left(\tilde{\mathrm{x}}_{\mathrm{ij}}\right) \\
& -\sum \mathrm{E}\left[\overline{\mathrm{u}} \eta_{\mathrm{i}}\right] \mathrm{E}\left(\tilde{\mathrm{x}}_{\mathrm{ij}}\right)=0
\end{aligned}
$$

since $\mathrm{E}\left(\eta_{\mathrm{i}}\right)=0$ and $\mathrm{E}\left(\tilde{\mathrm{x}}_{\mathrm{ij}}\right)=0$. 
Similarly,

$$
\begin{aligned}
\mathrm{E}\left(\mathrm{v}_{\mathrm{ij}} \mathrm{y}_{\mathrm{i}} \eta_{\mathrm{i}}\right) & =\mathrm{E}\left(\mathrm{v}_{\mathrm{ij}} \eta_{\mathrm{i}}\right) \mathrm{E}\left(\tilde{\mathrm{x}}_{\mathrm{i}} \beta\right)+\mathrm{E}\left[\mathrm{v}_{\mathrm{ij}}\left(\mathrm{u}_{\mathrm{i}}-\overline{\mathrm{u}}\right)\left(\mathrm{u}_{\mathrm{i}}-\mathrm{v}_{\mathrm{i}} \beta\right)\right] \\
& =\mathrm{E}\left(\mathrm{v}_{\mathrm{ij}}\right) \mathrm{E}\left[\left(\mathrm{u}_{\mathrm{i}}-\overline{\mathrm{u}}\right) \mathrm{u}_{\mathrm{i}}-\mathrm{E}\left(\mathrm{v}_{\mathrm{ij}} \mathrm{v}_{\mathrm{i}} \beta\right) \mathrm{E}\left(\mathrm{u}_{\mathrm{i}}-\overline{\mathrm{u}}\right)=0\right.
\end{aligned}
$$

3) $\underset{\mathrm{N} \rightarrow \infty}{\mathrm{E}}\left(\mathrm{z}_{3}^{\prime} \eta / \sqrt{\mathrm{N}}\right)=0$.

$$
\begin{aligned}
& \text { Again, } \mathrm{E}\left(\mathrm{z}_{3}^{\prime} \eta / \sqrt{\mathrm{N}}\right)=0 \text { since } \\
& \begin{aligned}
& \mathrm{E}\left(\mathrm{z}_{3}^{\prime} \eta / \sqrt{\mathrm{N}}\right)=(1 / \sqrt{\mathrm{N}}) \mathrm{E}\left[\sum\left(\mathrm{y}_{\mathrm{i}}^{2} \eta_{\mathrm{i}}\right)\right] \\
&=\mathrm{E} \sum\left[\left(\tilde{\mathrm{x}}_{\mathrm{i}} \beta\right)^{2}+\left(\mathrm{u}_{\mathrm{i}}-\overline{\mathrm{u}}\right)^{2}+2 \tilde{\mathrm{x}}_{\mathrm{i}} \beta\left(\mathrm{u}_{\mathrm{i}}-\overline{\mathrm{u}}\right)\right] \eta_{\mathrm{i}} . \\
& \mathrm{E} \sum\left(\tilde{\mathrm{x}}_{\mathrm{i}} \beta\right)^{2} \eta_{\mathrm{i}}=\sum \mathrm{E}\left[\left(\tilde{\mathrm{x}}_{\mathrm{i}} \beta\right)^{2}\right] \mathrm{E}\left(\eta_{\mathrm{i}}\right)=0, \\
& \mathrm{E} \sum \tilde{\mathrm{x}}_{\mathrm{i}} \beta\left(\mathrm{u}_{\mathrm{i}}-\overline{\mathrm{u}}\right) \eta_{\mathrm{i}}=\sum \mathrm{E}\left[\left(\mathrm{u}_{\mathrm{i}}-\overline{\mathrm{u}}\right) \eta_{\mathrm{i}}\right] \mathrm{E}\left(\tilde{\mathrm{x}}_{\mathrm{i}} \beta\right)=0 .
\end{aligned}
\end{aligned}
$$

Finally,

$$
\mathrm{E}\left(\mathrm{u}_{\mathrm{i}}-\overline{\mathrm{u}}\right)^{2} \eta_{\mathrm{i}}=\mathrm{E}\left(\mathrm{u}_{\mathrm{i}}-\overline{\mathrm{u}}\right)^{2} \mathrm{u}_{\mathrm{i}}-\mathrm{E}\left(\mathrm{u}_{\mathrm{i}}-\overline{\mathrm{u}}\right)^{2} \mathrm{v}_{\mathrm{i}} \beta=0
$$

Indeed, $E\left(u_{i}-\bar{u}\right)^{2} u_{i}=0$ because the $u_{i}^{\prime}$ s are normally distributed, and therefore, all their third order moments are equal to zero. Similarly,

$$
E\left(u_{i}-\bar{u}\right)^{2} V_{i}=E\left(u_{i}-\bar{u}\right)^{2} E\left(V_{i}\right)=0
$$

4) $\underset{\mathrm{N} \rightarrow \infty}{\mathrm{E}}\left(\mathrm{z}_{4}^{\prime} \eta / \sqrt{\mathrm{N}}\right)=0$. 
A typical element of $\mathrm{E}\left(\mathrm{z}_{4}^{\prime} \eta / \sqrt{\mathrm{N}}\right)$ is :

$$
\mathrm{E}\left(\mathrm{z}_{4 \mathrm{j}}^{\prime} \eta / \sqrt{\mathrm{N}}\right)=\mathrm{E}\left[\sum\left(\mathrm{x}_{\mathrm{ij}}^{3} \eta_{\mathrm{i}} / \sqrt{\mathrm{N}}\right)-3 \sum\left(\mathrm{c}_{\mathrm{jj}} \mathrm{x}_{\mathrm{ij}} \eta_{\mathrm{i}} / \sqrt{\mathrm{N}}\right)\right] \quad(\mathrm{j}=1, \ldots, \mathrm{K})
$$

where

$$
\begin{aligned}
c_{j j}=E\left(\sum x_{i j}^{2} / N\right)= & E\left(\sum \tilde{x}_{i j}^{2} / N\right)+\sigma_{v_{j}}^{2}-\sigma_{v_{j}}^{2} / N \\
& =E\left(\sum \tilde{x}_{i j}^{2} / N\right)+\sigma_{v_{j}}^{2}+O\left(N^{-1}\right)
\end{aligned}
$$

where $\sigma_{v_{j}}^{2}$ is the variance of the elements of $V_{j}$, the $j$ 'th column of $V$.

Now,

$$
\begin{aligned}
& \mathrm{E}\left(\sum \mathrm{x}_{\mathrm{ij}}^{3} \eta_{\mathrm{i}}-3 \sum \mathrm{c}_{\mathrm{ji}} \mathrm{x}_{\mathrm{ij}} \eta_{\mathrm{i}}\right) / \sqrt{\mathrm{N}} \\
& =(1 / \sqrt{\mathrm{N}}) \mathrm{E}\left(\sum \tilde{\mathrm{x}}_{\mathrm{ij}}^{3} \eta_{\mathrm{i}}+3 \sum \tilde{\mathrm{x}}_{\mathrm{ij}}^{2} \mathrm{v}_{\mathrm{ij}} \eta_{\mathrm{i}}+3 \sum \tilde{\mathrm{x}}_{\mathrm{ij}} \mathrm{v}_{\mathrm{ij}}^{2} \eta_{\mathrm{i}}+\sum \mathrm{v}_{\mathrm{ij}}^{3} \eta_{\mathrm{i}}\right. \\
& \left.-3 \mathrm{c}_{\mathrm{jj}} \sum \tilde{\mathrm{x}}_{\mathrm{ij}} \eta_{\mathrm{i}}-3 \mathrm{c}_{\mathrm{jj}} \sum \mathrm{v}_{\mathrm{ij}} \eta_{\mathrm{i}}\right) \\
& =(1 / \sqrt{\mathrm{N}}) \mathrm{E}\left(3 \sum \tilde{\mathrm{x}}_{\mathrm{ij}}^{2} \mathrm{v}_{\mathrm{ij}} \eta_{\mathrm{i}}+\sum \mathrm{v}_{\mathrm{ij}}^{3} \eta_{\mathrm{i}}-3 \mathrm{c}_{\mathrm{jj}} \sum \mathrm{v}_{\mathrm{ij}} \eta_{\mathrm{i}}\right),
\end{aligned}
$$

since the other terms are equal to zero and,

$$
\begin{aligned}
& (1 / \sqrt{\mathrm{N}}) \mathrm{E}\left(3 \sum \tilde{\mathrm{x}}_{\mathrm{ij}}^{2} \mathrm{v}_{\mathrm{ij}} \eta_{\mathrm{i}}+\sum \mathrm{v}_{\mathrm{ij}}^{3} \eta_{\mathrm{i}}-3 \sum \mathrm{c}_{\mathrm{jj}} \mathrm{v}_{\mathrm{ij}} \eta_{\mathrm{i}}\right) \\
& =-3 \mathrm{E}\left(\sum \tilde{\mathrm{x}}_{\mathrm{ij}}^{2}\right) \sum_{\mathrm{m}=1}^{\mathrm{K}} \mathrm{E}\left(\mathrm{v}_{\mathrm{ij}} \mathrm{v}_{\mathrm{im}} \beta_{\mathrm{m}}\right) / \sqrt{\mathrm{N}}-\sqrt{\mathrm{N}} \underset{\mathrm{m}=1}{\sum_{\mathrm{K}}^{\mathrm{K}}} \mathrm{E}\left(\mathrm{v}_{\mathrm{ij}}^{3} \mathrm{v}_{\mathrm{im}} \beta_{\mathrm{m}}\right) \\
& +3 \sqrt{\mathrm{N}} \mathrm{E}\left(\sum \tilde{\mathrm{x}}_{\mathrm{ij}}^{2} / \mathrm{N}\right) \underset{\mathrm{m}=1}{\mathrm{~K}} \mathrm{E}\left(\mathrm{v}_{\mathrm{ij}} \mathrm{v}_{\mathrm{im}} \beta_{\mathrm{m}}\right) \\
& +3 \sqrt{\mathrm{N}} \sigma_{\mathrm{v}_{\mathrm{j}}}^{2} \sum_{\mathrm{m}=1}^{\mathrm{K}} \mathrm{E}\left(\mathrm{V}_{\mathrm{ij}} \mathrm{V}_{\mathrm{im}} \beta_{\mathrm{m}}\right)+\mathrm{O}\left(\mathrm{N}^{-1 / 2}\right) .
\end{aligned}
$$


The first and third terms on the right-hand side of (A.20) cancel out. Since the $V_{i j}{ }^{\prime} s(j=1, \ldots, K)$ have a joint normal distribution, $\sqrt{\mathrm{N}} E\left(v_{i j}^{3} V_{i m}\right)=$ $3 \sqrt{\mathrm{N}} \sigma_{\mathrm{v}_{\mathrm{j}}}^{2} \mathrm{E}\left(\mathrm{V}_{\mathrm{ij}} \mathrm{V}_{\mathrm{im}}\right)+\mathrm{O}\left(\mathrm{N}^{-1 / 2}\right)(\mathrm{m}=1, \ldots, \mathrm{K})$ [Kendall and Stuart (1963), p. 91] and, hence, the second and fourth terms on the right-hand side of (A.18) cancel out as $\mathrm{N} \rightarrow \infty$, and so does the last term. Thus :

$\mathrm{E}\left(\mathrm{z}_{4}^{\prime} \eta / \sqrt{\mathrm{N}}\right)=0$

5) $\underset{\mathrm{N} \rightarrow \infty}{\mathrm{E}}\left(\mathrm{z}_{5}^{\prime} \eta / \sqrt{\mathrm{N}}\right)=0$.

A typical element of $E\left(z_{5}^{\prime} \eta / \sqrt{N}\right)$ is

$$
\begin{aligned}
\mathrm{E}\left(\mathrm{z}_{5 \mathrm{j}}^{\prime} \eta / \sqrt{\mathrm{N}}\right)= & (1 / \sqrt{\mathrm{N}}) \mathrm{E}\left\{\sum \mathrm{x}_{\mathrm{ij}}^{2} \mathrm{y}_{\mathrm{i}} \eta_{\mathrm{i}}-2\left[\mathrm{E} \sum \mathrm{x}_{\mathrm{ij}} \mathrm{y}_{\mathrm{i}} / \mathrm{N}\right] \sum \mathrm{x}_{\mathrm{ij}} \eta_{\mathrm{i}}\right. \\
& \left.-\mathrm{E}\left(\sum \mathrm{x}_{\mathrm{ij}}^{2} / \mathrm{N}\right) \sum \mathrm{y}_{\mathrm{i}} \eta_{\mathrm{i}}\right\} \quad(\mathrm{j}=1, \ldots, \mathrm{K}) .
\end{aligned}
$$

Now,

$E \sum x_{i j} y_{i} / N=E \sum\left(\tilde{x}_{i j}+v_{i j}\right)\left(\tilde{x}_{i} \beta+u_{i}-\bar{u}\right) / N=E \sum_{i=1}^{N} \tilde{x}_{i j} \tilde{x}_{i} \beta / N$.

Then,

$$
\begin{aligned}
& \mathrm{E}\left(\mathrm{z}_{5 \mathrm{j}}^{\prime} \eta / \sqrt{\mathrm{N}}\right)=\mathrm{E}\left\{\sum\left(\tilde{\mathrm{x}}_{\mathrm{ij}}^{2}+\mathrm{v}_{\mathrm{ij}}^{2}+2 \tilde{\mathrm{x}}_{\mathrm{ij}} \mathrm{v}_{\mathrm{ij}}\right)\left(\tilde{\mathrm{x}}_{\mathrm{i}} \beta+\mathrm{u}_{\mathrm{i}}-\overline{\mathrm{u}}\right) \eta_{\mathrm{i}} / \sqrt{\mathrm{N}}\right. \\
& -2\left[\mathrm{E}\left(\sum \tilde{\mathrm{x}}_{\mathrm{ij}} \tilde{\mathrm{x}}_{\mathrm{i}} \beta / \mathrm{N}\right)\right] \sum\left[\left(\tilde{\mathrm{x}}_{\mathrm{ij}}+\mathrm{v}_{\mathrm{ij}}\right) \eta_{\mathrm{i}}\right] / \sqrt{\mathrm{N}} \\
& -\left[\mathrm{E}\left(\sum \tilde{\mathrm{x}}_{\mathrm{ij}}^{2} / \mathrm{N}\right)\right] \sum\left[\left(\tilde{\mathrm{x}}_{\mathrm{i}} \beta+\mathrm{u}_{\mathrm{i}}-\overline{\mathrm{u}}\right) \eta_{\mathrm{i}}\right] / \sqrt{\mathrm{N}} \\
& \left.-\sigma_{\mathrm{v}_{\mathrm{j}}}^{2} \sum\left[\left(\tilde{\mathrm{x}}_{\mathrm{i}} \beta+\mathrm{u}_{\mathrm{i}}-\overline{\mathrm{u}}\right) \eta_{\mathrm{i}}\right] / \sqrt{\mathrm{N}}\right\}+\mathrm{O}\left(\mathrm{N}^{-1 / 2}\right)
\end{aligned}
$$




$$
\begin{aligned}
& =\mathrm{E}\left[\sum \tilde{\mathrm{x}}_{\mathrm{ij}}^{2}\right] \mathrm{E}\left[\left(\mathrm{u}_{\mathrm{i}}-\overline{\mathrm{u}}\right) \eta_{\mathrm{i}}\right] / \sqrt{\mathrm{N}}+\sqrt{\mathrm{N}} \mathrm{E}\left[\left(\mathrm{v}_{\mathrm{ij}}^{2}\left(\mathrm{u}_{\mathrm{i}}-\overline{\mathrm{u}}\right) \eta_{\mathrm{i}}\right]\right. \\
& +2 \mathrm{E}\left(\sum \tilde{\mathrm{x}}_{\mathrm{ij}} \tilde{\mathrm{x}}_{\mathrm{i}} \beta\right] \mathrm{E}\left(\mathrm{v}_{\mathrm{ij}} \eta_{\mathrm{i}}\right) / \sqrt{\mathrm{N}} \\
& -2 \sqrt{\mathrm{N}}\left[\mathrm{E}\left(\sum \tilde{\mathrm{x}}_{\mathrm{ij}} \tilde{\mathrm{x}}_{\mathrm{i}} \beta / \mathrm{N}\right)\right] \mathrm{E}\left(\mathrm{v}_{\mathrm{ij}} \eta_{\mathrm{i}}\right] \\
& -\sqrt{\mathrm{N}}\left(\mathrm{E} \sum \tilde{\mathrm{x}}_{\mathrm{ij}}^{2} / \mathrm{N}\right) \mathrm{E}\left[\left(\mathrm{u}_{\mathrm{i}}-\overline{\mathrm{u}}\right) \eta_{\mathrm{i}}\right] \\
& -\sqrt{\mathrm{N}} \sigma_{\mathrm{v}_{\mathrm{j}}}^{2} \mathrm{E}\left[\left(\mathrm{u}_{\mathrm{i}}-\overline{\mathrm{u}}\right) \eta_{\mathrm{i}}\right]+\mathrm{O}\left(\mathrm{N}^{-1 / 2}\right)
\end{aligned}
$$

The first and fifth terms on the right-hand side of equation (A.24) as well as the third and fourth terms cancel out. Finally, as $\mathrm{N} \rightarrow \infty$, the last term vanishes and the second and sixth terms cancel out since $u_{i}$ is independent of $v_{i}$ and, hence, for the second term, we have

$$
\begin{aligned}
& \mathrm{E}\left[\mathrm{v}_{\mathrm{ij}}^{2}\left(\mathrm{u}_{\mathrm{i}}-\overline{\mathrm{u}}\right) \eta_{\mathrm{i}}\right]=\mathrm{E}\left[\mathrm{v}_{\mathrm{ij}}^{2}\left(\mathrm{u}_{\mathrm{i}}-\overline{\mathrm{u}}\right)\left(\mathrm{u}_{\mathrm{i}}-\mathrm{v}_{\mathrm{i}} \beta\right)\right] \\
& =\mathrm{E}\left[\mathrm{v}_{\mathrm{ij}}^{2}\left(\mathrm{u}_{\mathrm{i}}-\overline{\mathrm{u}}\right) \mathrm{u}_{\mathrm{i}}\right]=\sigma_{\mathrm{v}_{\mathrm{j}}}^{2} \mathrm{E}\left[\left(\mathrm{u}_{\mathrm{i}}-\overline{\mathrm{u}}\right) \mathrm{u}_{\mathrm{i}}\right]+\mathrm{O}\left(\mathrm{N}^{-1}\right)
\end{aligned}
$$

and similarly, for the sixth term, we have :

$$
\sigma_{v_{j}}^{2} E\left[\left(u_{i}-\bar{u}\right) \eta_{i}\right]=\sigma_{v_{j}}^{2} E\left[\left(u_{i}-\bar{u}\right)\left(u_{i}-v_{i} \beta\right)=\sigma_{v_{j}}^{2} E\left[\left(u_{i}-\bar{u}\right) u_{i}\right]\right.
$$

6) $\underset{\mathrm{N} \rightarrow \infty}{\mathrm{E}}\left(\mathrm{z}_{6}^{\prime} \eta / \sqrt{\mathrm{N}}\right)=0$.

A typical element of $\mathrm{E}\left(\mathrm{z}_{6}^{\prime} \eta / \sqrt{\mathrm{N}}\right)$ is

$$
\begin{aligned}
& \mathrm{E}\left(\mathrm{z}_{6 \mathrm{j}}^{\prime} \eta / \sqrt{\mathrm{N}}\right)=\mathrm{E}\left\{\sum \mathrm{x}_{\mathrm{ij}} \mathrm{y}_{\mathrm{i}}^{2} \eta_{\mathrm{i}} / \sqrt{\mathrm{N}}-\mathrm{E}\left(\mathrm{y}^{\prime} \mathrm{y} / \mathrm{N}\right) \sum \mathrm{x}_{\mathrm{ij}} \eta_{\mathrm{i}} / \sqrt{\mathrm{N}}\right. \\
& \left.-2\left[\mathrm{E} \sum \mathrm{x}_{\mathrm{ij}} \mathrm{y}_{\mathrm{i}} / \mathrm{N}\right] \sum \mathrm{y}_{\mathrm{i}} \eta_{\mathrm{i}} / \sqrt{\mathrm{N}}\right\} \quad(\mathrm{j}=1, \ldots, \mathrm{K}) .
\end{aligned}
$$


Now,

$\mathrm{E} \mathrm{y}^{\prime} \mathrm{y} / \mathrm{N}=\beta^{\prime} \mathrm{E}\left(\tilde{\mathrm{x}}^{\prime} \tilde{\mathrm{x}} / \mathrm{N}\right) \beta+\sigma_{\mathrm{u}}^{2}+\mathrm{O}\left(\mathrm{N}^{-1}\right)$

and therefore

$$
\begin{aligned}
& \mathrm{E}\left(\mathrm{z}_{6 \mathrm{j}}^{\prime} \eta / \sqrt{\mathrm{N}}\right)=\mathrm{E}\left[\sum \left\{( \tilde { \mathrm { x } } _ { \mathrm { ij } } + \mathrm { v } _ { \mathrm { ij } } ) \left[\left(\tilde{\mathrm{x}}_{\mathrm{i}} \beta\right)^{2}+\left(\mathrm{u}_{\mathrm{i}}-\overline{\mathrm{u}}\right)^{2}\right.\right.\right. \\
& \left.\left.+2 \tilde{\mathrm{x}}_{\mathrm{i}} \beta\left(\mathrm{u}_{\mathrm{i}}-\overline{\mathrm{u}}\right)\right] \eta_{\mathrm{i}} / \sqrt{\mathrm{N}}\right\} \\
& -\left[\beta^{\prime} \mathrm{E}\left(\tilde{\mathrm{x}}^{\prime} \tilde{\mathrm{x}} / \mathrm{N}\right) \beta+\sigma_{\mathrm{u}}^{2}\right] \sum\left[\left(\tilde{\mathrm{x}}_{\mathrm{ij}}+\mathrm{v}_{\mathrm{ij}}\right) \eta_{\mathrm{i}} / \sqrt{\mathrm{N}}\right] \\
& \left.\left.-2 \mathrm{E}\left(\sum \tilde{\mathrm{x}}_{\mathrm{ij}} \tilde{\mathrm{x}}_{\mathrm{i}} \beta / \mathrm{N}\right) \sum\left[\left(\tilde{\mathrm{x}}_{\mathrm{i}} \beta+\mathrm{u}_{\mathrm{i}}-\overline{\mathrm{u}}\right) \eta_{\mathrm{i}}\right] / \sqrt{\mathrm{N}}\right\}\right]+\mathrm{O}\left(\mathrm{N}^{-1 / 2}\right) \\
& \left.=2\left[\mathrm{E} \sum \tilde{\mathrm{x}}_{\mathrm{ij}} \tilde{\mathrm{x}}_{\mathrm{i}} \beta\right] \mathrm{E}\left[\left(\mathrm{u}_{\mathrm{i}}-\overline{\mathrm{u}}\right) \eta_{\mathrm{i}}\right] / \sqrt{\mathrm{N}}+\left[\mathrm{E}\left(\beta^{\prime} \tilde{\mathrm{x}}^{\prime} \tilde{\mathrm{x}} \beta\right)\right] \mathrm{E}\left(\mathrm{v}_{\mathrm{ij}} \eta_{\mathrm{i}}\right) / \sqrt{\mathrm{N}}\right) \\
& +\sqrt{\mathrm{N}} \mathrm{E}\left[\left(\mathrm{v}_{\mathrm{ij}}\left(\mathrm{u}_{\mathrm{i}}-\overline{\mathrm{u}}\right)^{2} \eta_{\mathrm{i}}\right]-\sqrt{\mathrm{N}} \beta^{\prime} \mathrm{E}(\tilde{\mathrm{x}} \tilde{\mathrm{x}} / \mathrm{N}) \beta \mathrm{E}\left(\mathrm{v}_{\mathrm{ij}} \eta_{\mathrm{i}}\right)\right. \\
& -\sigma_{\mathrm{u}}^{2} \sqrt{\mathrm{N}} \mathrm{E}\left(\mathrm{v}_{\mathrm{ij}} \eta_{\mathrm{i}}\right)-2 \sqrt{\mathrm{N}} \mathrm{E}\left(\sum \tilde{\mathrm{x}}_{\mathrm{ij}} \tilde{\mathrm{x}}_{\mathrm{i}} \beta / \mathrm{N}\right) \mathrm{E}\left[\left(\mathrm{u}_{\mathrm{i}}-\overline{\mathrm{u}}\right) \eta_{\mathrm{i}}\right]+\mathrm{O}\left(\mathrm{N}^{-1 / 2}\right) .
\end{aligned}
$$

The first and sixth terms on the right-hand side of (A.30), as well as the second and fourth terms cancel out. Now, for the third term,

$$
\begin{aligned}
\sqrt{\mathrm{N}} \mathrm{E}\left[\mathrm{v}_{\mathrm{ij}}\left(\mathrm{u}_{\mathrm{i}}-\overline{\mathrm{u}}\right)^{2} \eta_{\mathrm{i}}\right] & =\sqrt{\mathrm{N}} \mathrm{E}\left[\left(\mathrm{u}_{\mathrm{i}}-\overline{\mathrm{u}}\right)^{2} \mathrm{v}_{\mathrm{ij}}\left(\mathrm{u}_{\mathrm{i}}-\mathrm{v}_{\mathrm{i}} \beta\right)\right] \\
= & -\sqrt{\mathrm{N}} \sigma_{\mathrm{u}}^{2} \mathrm{E}\left(\mathrm{v}_{\mathrm{ij}} \mathrm{v}_{\mathrm{i}} \beta\right)+\mathrm{O}\left(\mathrm{N}^{-1 / 2}\right)
\end{aligned}
$$

and for the fifth term,

$$
\begin{aligned}
& \sqrt{\mathrm{N}} \sigma_{\mathrm{u}}^{2} \mathrm{E}\left[\mathrm{v}_{\mathrm{ij}} \eta_{\mathrm{i}}\right)=\sigma_{\mathrm{u}}^{2} \mathrm{E}\left[\mathrm{v}_{\mathrm{ij}}\left(\mathrm{u}_{\mathrm{i}}-\mathrm{V}_{\mathrm{i}} \beta\right)\right] \\
& =-\sqrt{\mathrm{N}} \sigma_{\mathrm{u}}^{2} \mathrm{E}\left(\mathrm{v}_{\mathrm{ij}} \mathrm{v}_{\mathrm{i}} \beta\right),
\end{aligned}
$$


and hence, the third and fifth terms also cancel out, as $\mathrm{N} ! \infty$, and so does the last term.

7) $\underset{\mathrm{N} \rightarrow \infty}{\mathrm{E}}\left(\mathrm{z}_{7}^{\prime} \eta / \sqrt{\mathrm{N}}\right)=0$.

We have

$$
\begin{aligned}
& \mathrm{E}\left(\mathrm{z}_{7}^{\prime} \eta / \sqrt{\mathrm{N}}\right)=\mathrm{E}\left[\sum\left(\mathrm{y}_{\mathrm{i}}^{3} \eta_{\mathrm{i}} / \sqrt{\mathrm{N}}\right)-3\left(\mathrm{E} \mathrm{y}^{\prime} \mathrm{y} / \mathrm{N}\right) \sum\left(\mathrm{y}_{\mathrm{i}} \eta_{\mathrm{i}} / \sqrt{\mathrm{N}}\right)\right] \\
& \mathrm{E}\left(\mathrm{z}_{7}^{\prime} \mathrm{n}\right)=\mathrm{E}\left\{\sum \left[\left(\tilde{\mathrm{x}}_{\mathrm{i}} \beta\right)^{3}+3\left(\tilde{\mathrm{x}}_{\mathrm{i}} \beta\right)^{2}\left(\mathrm{u}_{\mathrm{i}}-\overline{\mathrm{u}}\right)\right.\right. \\
& \left.+3\left(\tilde{\mathrm{x}}_{\mathrm{i}} \beta\right)\left(\mathrm{u}_{\mathrm{i}}-\overline{\mathrm{u}}\right)^{2}+\left(\mathrm{u}_{\mathrm{i}}-\overline{\mathrm{u}}\right)^{3}\right] \eta_{\mathrm{i}} / \sqrt{\mathrm{N}} \\
& -3\left[\beta^{\prime} \mathrm{E}\left(\tilde{\mathrm{x}}^{\prime} \tilde{\mathrm{x}} / \mathrm{N}\right) \beta+\sigma_{\mathrm{u}}^{2}\right]\left[\left[\left(\tilde{\mathrm{x}}_{\mathrm{i}} \beta+\mathrm{u}_{\mathrm{i}}-\overline{\mathrm{u}}\right) \eta_{\mathrm{i}}\right] / \sqrt{\mathrm{N}}\right\}+\mathrm{O}\left(\mathrm{N}^{-1 / 2}\right) \\
& =3 \mathrm{E}\left(\beta^{\prime} \tilde{\mathrm{x}}^{\prime} \tilde{\mathrm{x}} \beta\right) \mathrm{E}\left[\left(\mathrm{u}_{\mathrm{i}}-\overline{\mathrm{u}}\right) \eta_{\mathrm{i}}\right] / \sqrt{\mathrm{N}}+\sqrt{\mathrm{N}} \mathrm{E}\left[\left(\mathrm{u}_{\mathrm{i}}-\overline{\mathrm{u}}\right)^{3} \eta_{\mathrm{i}}\right] \\
& -3 \sqrt{\mathrm{N}} \beta^{\prime}\left[\mathrm{E}\left(\tilde{\mathrm{x}} \tilde{\mathrm{x}}^{\prime} / \mathrm{N}\right)\right] \beta \mathrm{E}\left[\left(\mathrm{u}_{\mathrm{i}}-\overline{\mathrm{u}}\right) \eta_{\mathrm{i}}\right] \\
& -3 \sigma_{\mathrm{u}}^{2} \sqrt{\mathrm{N}} \mathrm{E}\left[\left(\mathrm{u}_{\mathrm{i}}-\overline{\mathrm{u}}\right) \eta_{\mathrm{i}}\right]+\mathrm{O}\left(\mathrm{N}^{-1 / 2}\right) .
\end{aligned}
$$

The first and third terms of the right-hand side of equation (A.35) cancel out. As $\mathrm{N} \rightarrow \infty$, the last term vanishes and the second and fourth terms also cancel out since,

$$
\begin{aligned}
& \sqrt{\mathrm{N}} \mathrm{E}\left[\left(\mathrm{u}_{\mathrm{i}}-\overline{\mathrm{u}}\right)^{3} \eta_{\mathrm{i}}\right]=\sqrt{\mathrm{N}} \mathrm{E}\left(\mathrm{u}_{\mathrm{i}}^{4}\right)+\mathrm{O}\left(\mathrm{N}^{-1 / 2}\right), \\
& \sqrt{\mathrm{N}} \sigma_{\mathrm{u}}^{2} \mathrm{E}\left[\mathrm{u}_{\mathrm{i}}-\overline{\mathrm{u}}\right) \eta_{\mathrm{i}}=\sqrt{\mathrm{N}} \sigma_{\mathrm{u}}^{4}+\mathrm{O}\left(\mathrm{N}^{-1 / 2}\right)
\end{aligned}
$$

and, given that $\mathrm{u}$ is normally distributed,

$$
\mathrm{E}\left(\mathrm{u}_{\mathrm{i}}^{4}\right)=3 \sigma_{\mathrm{u}}^{4}
$$




\section{APPENDIX B}

\section{THE ASYMPTOTIC COVARIANCE MATRIX OF $\boldsymbol{\theta}$}

The asymptotic covariance matrix of $\widetilde{\theta}$ can be derived as follows. Replacing $\hat{Y}$ in equation (12) that defines $\widetilde{\theta}$, by its value in equation (13), and then replacing $\mathrm{Y}$ in equations (13) and (15) and by its value in equation (4), one obtains :

$$
\begin{aligned}
& \hat{\mathrm{Y}}=\left(l_{\mathrm{N}}, \hat{\mathrm{X}}\right) \theta+\mathrm{Z}\left(\mathrm{Z}^{\prime} \mathrm{Z}\right)^{-1} \mathrm{Z}^{\prime} \eta \\
& \mathrm{S}_{21}=\mathrm{S}_{22} \theta+\left[\left(l_{\mathrm{N}}, \mathrm{X}\right)^{\prime}-\left(l_{\mathrm{N}}, \mathrm{X}\right)^{\prime} \mathrm{Z}\left(\mathrm{Z} \mathrm{Z}^{-1} \mathrm{Z}^{\prime}\right] \eta /(\mathrm{N}-\mathrm{q})\right.
\end{aligned}
$$

and

$$
\begin{aligned}
& \widetilde{\theta}=\theta+\left\{\left[\left(l_{\mathrm{N}}, \hat{\mathrm{X}}\right)^{\prime}\left(l_{\mathrm{N}}, \hat{\mathrm{X}}\right)-(\tilde{v}-\gamma) \mathrm{S}_{22}\right] / \mathrm{N}\right\}^{-1} \\
& {\left[\left(l_{\mathrm{N}}, \hat{\mathrm{X}}\right)^{\prime} \mathrm{Z}(\mathrm{Z} \mathrm{Z})^{-1}\right] \mathrm{Z}^{\prime} \eta / \mathrm{N}+\mathrm{O}_{\mathrm{p}}\left(\mathrm{N}^{-1}\right)}
\end{aligned}
$$

Hence,

$\sqrt{\mathrm{N}}(\widetilde{\theta}-\theta)$ has the same asymptotic distribution [Theil (1971)] as

$$
\begin{aligned}
& \Lambda=\left[\operatorname{Plim}\left\{\left[\left(l_{N}, \hat{X}\right)^{\prime}\left(l_{N}, \hat{X}\right)-(\tilde{v}-\gamma) S_{22}\right] / N\right\}\right]^{-1} \\
& \left\{P \lim \left[\left(l_{N}, \hat{X}\right)^{\prime} Z / N\right]\left[P \lim (Z Z / N)^{-1}\right]\right\} Z^{\prime} \eta / \sqrt{N} .
\end{aligned}
$$

$\Lambda$ is asymptotically normally distributed [White (1984)] with mean 0 and covariance matrix :

$$
\mathrm{V}=\mathrm{E}\left(\Lambda \Lambda^{\prime}\right)=\left[(\mathrm{Plim} \mathrm{A})^{-1} \mathrm{Plim} \mathrm{B}\right] \mathrm{E}\left[\mathrm{Z}^{\prime} \eta \eta^{\prime} \mathrm{Z} / \mathrm{N}\right] \mathrm{Plim} \mathrm{B}^{\prime}(\mathrm{Plim} \mathrm{A})^{-1}
$$

where $\mathrm{A}$ and $\mathrm{B}$ are defined in equations (17) and (18). 
Since the random variables included in $\mathrm{Z}$ and $\eta$ are not correlated between observations, E[Z' $\left.\eta \eta^{\prime} \mathrm{Z} / \mathrm{N}\right]$ can be estimated by $\sum_{\mathrm{i}=1}^{\mathrm{N}} \mathrm{Z}_{\mathrm{i}}^{\prime} \mathrm{Z}_{\mathrm{i}} \tilde{\eta}_{\mathrm{i}}^{2} / \mathrm{N}$ [White (1984)] as indicated in equation (16). 


\section{REFERENCES}

Aigner, D.J., C. Hsiao, A. Kapteyn and T. Wansbeek, 1984, Latent Variable Models in Econometrics, in Z. Griliches and M.D. Intriligator (eds.), Handbook of Econometrics 2, (North Holland, Amsterdam), Chapter 23, 1321-1393.

Altonji, J.G. and A. Siow, 1987, Testing the Response of Consumption to Income Changes with (Noisy) Panel Data, The Quarterly Journal of Economics, May, 293-328.

Avery, R.B., 1991, Household Saving in the U.S., Review of Income and Wealth 37(4), 409-432.

Avery, R.B., G.E. Elliehausen and A.B. Kennickell, 1988, Measuring Wealth with Survey Data : An Evaluation of the 1983 Survey of Consumer Finances, Review of Income and Wealth 34(4), 339-369.

Bound, J. and A.B. Krueger, 1991, The Extent of Measurement Error in Longitudinal Earnings Data : Do Two Wrongs Make a Right?, Journal of Labor Economics 9, $1-24$.

Bowden, R.J., 1984, Instrumental Variables, (Cambridge University Press, Cambridge), 277 pages.

Dagenais, M.G., 1992, Measuring Personal Savings, Consumption and Disposable Income in Canada, Canadian Journal of Economics XXV(3), August, 681-707. 
Dagenais, M.G., 1994, Parameter Estimation in Regression Models with Errors in the Variables and Autocorrelated Disturbances, Journal of Econometrics 64, $145-163$.

Dagenais, M.G. and D.L. Dagenais, 1993, Estimation and Testing in Regression Models with Errors in the Variables, Discussion Paper No. IEA-93-03, Institut d'economie appliquee, (Ecole des Hautes Etudes Commerciales, Montreal), February.

Dagenais, M.G. and D.L. Dagenais, 1994, GMM Estimators for Linear Regression Models with Errors in the Variables, Discussion Paper No. 0594, Centre de Recherche et Developpement en Economique, (Universite de Montreal, Montreal), April.

Davidson, R. and J.G. MacKinnon, 1993, Estimation and Inference in Econometrics, (Oxford University Press, Oxford).

Drion, E.F., 1951, Estimation of the Parameters of a Straight Line and of the Variance of the Variables, if They Are Both Subject to Error, Indagationes Mathematicae 13, 256-260.

Duncan, G.J. and D.H. Hill, 1985, An Investigation of the Extent and Consequences of Measurement Errors in Labor-Economic Survey Data, Journal of Labor Economics 3(4), 508-532.

Durbin, J., 1954, Errors in Variables, International Statistical Review 22, 23-32. 
Fomby, T.B. and D.K. Guilkey, 1978, On Choosing the Optimal Level of Significance for the Durbin-Watson Test and the Bayesian Alternative, Journal of Econometrics 8, 203-214.

Fuller, W.A., 1987, Measurement Error Models, (Wiley, New York).

Geary, R.C., 1942, Inherent Relations Between Random Variables, Proc. Royal Irish Academy 47, 63-76.

Goldberger, A.S., 1972, Structural Equation Methods in the Social Sciences, Econometrica 40(6), 979-1002.

Gourieroux, C. and A. Montfort, 1989, Statistique et modeles econometriques, Volume 1, (Economica, Paris).

Grether, D.M. and G.S. Maddala, 1973, Errors in Variables and Serially Correlated Disturbances in Distributed Lag Models, Econometrica 41, 255-262.

Griliches, Z., 1986, Economic Data Issues, in Z. Griliches and M.D. Intriligator (eds.), Handbook of Econometrics 3, (North Holland, Amsterdam), Chapter 25, $1465-1514$.

Griliches, Z. and J.A. Hausman, 1986, Errors in Variables in Panel Data, Journal of Econometrics 31, 93-118.

Hansen, L.P., 1982, Large Sample Properties of Generalized Method of Moments Estimators, Econometrica 50(4), July, 1029-1054. 
Hausman, J.D., 1978, Specification Tests in Econometrics, Econometrica 46(6), November, 1251-1271.

Johnson, N.L. and S. Kotz, 1970a, Continuous Univariate Distributions-1, (Houghton Mifflin Co., Boston).

Johnson, N.L. and S. Kotz, 1970b, Continuous Univariate Distributions-2, (Houghton Mifflin Co., Boston).

Jeong, J. and G.S. Maddala, 1991, Measurement Errors and Tests for Rationality, Journal of Business and Economic Statistics 9(4), October, 431-439.

Kendall, M.G. and A. Stuart, 1963, The Advanced Theory of Statistics, Second edition, volume 1, (Charles Griffin and Company Limited, London).

Klepper, S. and E.E. Leamer, 1984, Consistent Sets of Estimates for Regressions with Errors in All Variables, Econometrica 52(1), 163-184.

Langaskens, Y. and M. Van Rickeghem, 1974, A New Method to Estimate Measurement Errors in National Income Account Statistics : The Belgian Case, International Statistical Review 42(3), 283-290.

Malinvaud, E., 1978, Methodes Statistiques de l'Econometrie, 3e edition, (Dunod, Paris).

Mankiw, N.G., D. Romer and D.N. Weil, 1992, A Contribution to the Empirics of Economic Growth, The Quarterly Journal of Economics, May, 407-437. 
Mariano, R.S. and T. Sawa, 1972, The Exact Finite-Sample Distribution of the Limited-Information Maximum Likelihood Estimator in the Case of Two Included Endogenous Variables, Journal of the American Statistical Association, March, 159-163.

Morgenstern, O., 1963, On the Accuracy of Economic Observations, Second edition, (Princeton University Press, Princeton, N.J).

Nelson, C.R., 1990, Some Further Results on the Exact Small Sample Properties of the Instrumental Variable Estimator, Econometrica 58(4), July, 967-976.

Pal, M., 1980, Consistent Moment Estimators of Regression Coefficients in the Presence of Errors in Variables, Journal of Econometrics 14(3), December, 349-364.

Radner, D.B., 1982, Social Security Bulletin 45(7), July, 13-21.

Reiersol, O., 1950, Identifiability of a Linear Relation Between Variables which are Subject to Error, Econometrica 18, 375-389.

Rodgers, W.L., C. Brown and G.J. Duncan, 1993, Errors in Survey Reports of Earnings, Hours Worked and Hourly Wages, Journal of the American Statistical Association 88(424), 1208-1218.

Statistics Canada, 1988, Family Expenditure in Canada, 1986, Survey of Family Expenditure, Public Use Microdata file. 
Theil, H., 1971, Principles of Econometrics, (Wiley, New York).

White, H., 1984, Asymptotic Theory for Econometricians, (Academic Press Inc., Orlando).

Wu, D., 1973, Alternative Tests of Independence Between Stochastic Regressors and Disturbances, Econometrica 41, 733-750. 
Table 1

Root Mean-Squared Errors - Experiment 1

$\left(\mathrm{N}=2,000 ; \mathbf{R}^{2}=0.4 ; \lambda_{1}=0.3\right)$

A) Root Mean-Squared Errors

\begin{tabular}{|c|c|c|c|c|c|}
\hline & $\theta_{d}$ & $\theta_{\mathrm{p}}$ & $\hat{\theta}$ & $\theta^{*}$ & $\widetilde{\theta}$ \\
\hline $\bar{\alpha}$ & 1.811 & 0.422 & 0.859 & 0.328 & 0.325 \\
\hline$\beta_{1}$ & 0.319 & 0.139 & 0.238 & 0.084 & 0.084 \\
\hline$\beta_{2}$ & 1.566 & 0.307 & 0.130 & 0.215 & 0.220 \\
\hline$\beta_{3}$ & 0.414 & 1.563 & 0.134 & 0.164 & 0.169 \\
\hline \multicolumn{2}{|c|}{$\begin{array}{l}\text { Average } \\
\text { RMSE } 1028\end{array}$} & 0.608 & 0.340 & 0.198 & 0.200 \\
\hline
\end{tabular}

B) Multiple $\mathrm{R}^{2}$ with Set of Instruments

\begin{tabular}{cccccc}
\hline Variable & $(1)$ & $(2)$ & $(3)$ & $(4)$ & $(5)$ \\
& $\theta_{\mathrm{d}}$ & $\theta_{\mathrm{p}}$ & $\theta^{*}$ & $\widetilde{\theta}$ & $\left(\widetilde{\theta}-\theta^{*}\right) \dagger$ \\
\hline$\tilde{\mathrm{X}}_{1}$ & 0.075 & 0.181 & 0.253 & 0.289 & 0.181 \\
$\tilde{\mathrm{X}}_{2}$ & 0.097 & 0.300 & 0.318 & 0.365 & 0.066 \\
$\tilde{\mathrm{X}}_{3}$ & 0.297 & 0.007 & 0.385 & 0.399 & 0.088 \\
\hline
\end{tabular}

$\dagger \quad$ This column shows the multiple $\mathrm{R}^{2}$ of each $\tilde{\mathrm{X}}_{\mathrm{i}}(\mathrm{i}=1,2,3)$ with $\left(l_{\mathrm{N}}, \overline{\mathrm{Z}}\right)$ where $\overline{\mathrm{Z}}$ corresponds to the subset of instruments included in $\mathrm{Z}$ but not in $\widetilde{\mathrm{Z}}$. $\overline{\mathrm{Z}}$ is defined as : $\overline{\mathrm{Z}}=\left(\mathrm{z}_{2}, \mathrm{z}_{3}, \mathrm{z}_{5}, \mathrm{z}_{6}, \mathrm{z}_{7}\right)$. 
Table 2

Biases, Type I Errors and EV Tests - Experiment 1

$$
\left(\mathrm{N}=2,000 ; \mathrm{R}^{2}=0.4 ; \lambda_{1}=0.3\right)
$$

A) Biases

\begin{tabular}{lccc}
\hline & $\hat{\theta}$ & $\theta^{*}$ & $\widetilde{\theta}$ \\
\hline$\alpha$ & 0.844 & 0.011 & -0.031 \\
$\beta_{1}$ & -0.236 & -0.004 & 0.010 \\
$\beta_{2}$ & -0.047 & -0.004 & 0.009 \\
$\beta_{3}$ & 0.103 & 0.006 & -0.005 \\
$\begin{array}{l}\text { Average of } \\
\text { absolute values }\end{array}$ & 0.308 & & \\
\hline
\end{tabular}

B) Size of Type I Errors, in \%

\begin{tabular}{lrrr}
\hline & $\hat{\theta}$ & $\theta^{*}$ & $\widetilde{\theta}$ \\
\hline$\alpha$ & 100.00 & 4.80 & 6.50 \\
$\beta_{1}$ & 100.00 & 5.20 & 6.60 \\
$\beta_{2}$ & 7.40 & 4.90 & 5.50 \\
$\beta_{3}$ & 24.40 & 5.10 & 5.90 \\
\hline
\end{tabular}

C) Power of EV Tests

Test based on $\tilde{Z}: 85.10 \%$

Test based on Z : $90.10 \%$ 
Table 3

Results of Experiment 2

$$
\left(\mathrm{N}=2,000 ; \mathrm{R}^{2}=0.4 ; \lambda_{1}=0.1\right)
$$

A) Biases

\begin{tabular}{lccc}
\hline & $\hat{\theta}$ & $\theta^{*}$ & $\widetilde{\theta}$ \\
\hline$\alpha$ & 0.334 & 0.007 & -0.008 \\
$\beta_{1}$ & -0.093 & -0.001 & 0.005 \\
$\beta_{2}$ & -0.019 & 0.004 & 0.011 \\
$\beta_{3}$ & 0.042 & 0.001 & -0.003 \\
$\begin{array}{l}\text { Average of } \\
\text { absolute values }\end{array}$ & 0.122 & 0.003 & 0.007 \\
\hline
\end{tabular}

B) Root Mean-Squared Errors

\begin{tabular}{llll}
\hline & $\hat{\theta}$ & $\theta^{*}$ & $\tilde{\theta}$ \\
\hline$\alpha$ & 0.370 & 0.257 & 0.261 \\
$\beta_{1}$ & 0.098 & 0.055 & 0.057 \\
$\beta_{2}$ & 0.117 & 0.202 & 0.208 \\
$\beta_{3}$ & 0.093 & 0.143 & 0.148 \\
Average & 0.169 & 0.164 & 0.168
\end{tabular}

C) Size of Type I Errors, in \%

\begin{tabular}{lrrr}
\hline & $\hat{\theta}$ & $\theta^{*}$ & $\hat{\theta}$ \\
\hline$\alpha$ & 58.00 & 6.30 & 6.30 \\
$\beta_{1}$ & 84.70 & 4.80 & 5.60 \\
$\beta_{2}$ & 5.20 & 4.30 & 4.30 \\
$\beta_{3}$ & 7.90 & 3.90 & 4.30 \\
\hline
\end{tabular}

D) Power of EV Tests

Test based on $\widetilde{Z}: 45.30 \%$

Test based on Z : $50.30 \%$ 
Table 4

Results of Experiment 3

$\left(\mathrm{N}=700 ; \mathrm{R}^{2}=0.4 ; \lambda_{1}=0.30\right)$

A) Biases

\begin{tabular}{lccc}
\hline & $\hat{\theta}$ & $\theta^{*}$ & $\widetilde{\theta}$ \\
\hline$\alpha$ & 0.853 & 0.026 & -0.093 \\
$\beta_{1}$ & -0.237 & -0.009 & 0.036 \\
$\beta_{2}$ & -0.412 & -0.006 & 0.047 \\
$\beta_{3}$ & 0.103 & 0.008 & 0.027 \\
$\begin{array}{l}\text { Average of } \\
\text { absolute values }\end{array}$ & 0.309 & 0.012 & 0.051 \\
\hline
\end{tabular}

B) Root Mean-Squared Errors

\begin{tabular}{llll}
\hline & $\hat{\theta}$ & $\theta^{*}$ & $\tilde{\theta}$ \\
\hline$\alpha$ & 0.891 & 0.540 & 0.614 \\
$\beta_{1}$ & 0.242 & 0.133 & 0.169 \\
$\beta_{2}$ & 0.200 & 0.374 & 0.402 \\
$\beta_{3}$ & 0.174 & 0.263 & 0.309 \\
Average & 0.377 & 0.328 & 0.374 \\
\hline
\end{tabular}

C) Size of Type I Error, in \%

\begin{tabular}{lccc}
\hline & $\hat{\theta}$ & $\theta^{*}$ & $\widetilde{\theta}$ \\
\hline$\alpha$ & 90.10 & 4.00 & 6.30 \\
$\beta_{1}$ & 99.80 & 4.00 & 7.00 \\
$\beta_{2}$ & 6.20 & 4.70 & 4.70 \\
$\beta_{3}$ & 9.20 & 3.90 & 5.50 \\
\hline
\end{tabular}

D) Power of EV Tests

Test based on $\widetilde{Z}: 36.70 \%$

Test based on Z : $51.60 \%$ 
Table 5

Results of Experiment 5

$\left(\mathrm{N}=2,000 ; \mathrm{R}^{2}=0.4 ; \lambda_{1}=0.30 ; \mathrm{r}_{13}=0.5 ; \beta_{3}=0\right)$

A) Biases

\begin{tabular}{lccr}
\hline & $\hat{\theta}$ & $\theta^{*}$ & $\widetilde{\theta}$ \\
\hline$\alpha$ & 1.926 & 0.060 & -0.104 \\
$\beta_{1}$ & -0.287 & -0.006 & 0.019 \\
$\beta_{2}$ & -0.065 & 0.011 & 0.016 \\
$\beta_{3}$ & 0.358 & 0.010 & -0.026 \\
$\begin{array}{l}\text { Average of } \\
\text { absolute values }\end{array}$ & 0.659 & 0.022 & 0.045 \\
\hline
\end{tabular}

B) Root Mean-Squared Errors

\begin{tabular}{llll}
\hline & $\hat{\theta}$ & $\theta^{*}$ & $\widetilde{\theta}$ \\
\hline$\alpha$ & 1.944 & 0.698 & 0.719 \\
$\beta_{1}$ & 0.289 & 0.095 & 0.100 \\
$\beta_{2}$ & 0.124 & 0.179 & 0.179 \\
$\beta_{3}$ & 0.367 & 0.182 & 0.195 \\
Average & 0.681 & 0.288 & 0.298
\end{tabular}

C) Size of Type I Error, in \%

\begin{tabular}{lrrr}
\hline & $\hat{\theta}$ & $\theta^{*}$ & $\tilde{\theta}$ \\
\hline$\alpha$ & 100.00 & 3.90 & 7.30 \\
$\beta_{1}$ & 100.00 & 4.80 & 7.10 \\
$\beta_{2}$ & 10.00 & 4.70 & 5.40 \\
$\beta_{3}$ & 99.30 & 4.10 & 5.70 \\
\hline
\end{tabular}

D) Power of EV Tests

Test based on $\widetilde{Z}: 84.00 \%$

Test based on Z : $89.40 \%$ 
Table 6

Human Capital Augmented Solow Model

[Mankiw, Romer and Weil (1992)]

Dependent Variable : ln GDP Per Capita in 1985.

Observations : Cross Section of 98 Countries

\section{A) Complete Set of Instruments}

\begin{tabular}{|c|c|c|c|c|c|}
\hline Estimator & $\begin{array}{c}\hat{\theta} \\
\text { (Standard error) }\end{array}$ & $\begin{array}{c}\theta^{*} \\
\text { (Standard error) }\end{array}$ & $\begin{array}{c}\tilde{\theta} \\
\text { (Standard error) }\end{array}$ & $\begin{array}{l}\text { EV Tests } \\
\text { Using Z̃. } \\
\text { t-Statistics }\end{array}$ & $\begin{array}{l}\text { EV Tests } \\
\text { Using Z. } \\
\text { t-Statistics }\end{array}$ \\
\hline Constant & $\begin{array}{l}6.848 \\
(1.177)\end{array}$ & $\begin{array}{c}2.884 \\
(1.799)\end{array}$ & $\begin{array}{l}3.856 \\
(2.737)\end{array}$ & & \\
\hline $\begin{array}{l}\ln (\mathrm{I} / \mathrm{GDP}) \\
\text { Investment/GDP }\end{array}$ & $\begin{array}{c}0.697 \\
(0.133)\end{array}$ & $\begin{array}{c}0.786 \\
(0.269)\end{array}$ & $\begin{array}{c}1.279 \\
(0.666)\end{array}$ & -0.534 & -1.679 \\
\hline $\begin{array}{l}\ln (\mathrm{n}+\mathrm{g}+\delta) \\
\text { Growth rates of labor } \\
\text { and capital plus } \\
\text { depreciation rate }\end{array}$ & $\begin{array}{l}-1.744 \\
(0.416)\end{array}$ & $\begin{array}{l}-3.205 \\
(0.628)\end{array}$ & $\begin{array}{l}-3.033 \\
(0.912)\end{array}$ & 3.278 & 2.506 \\
\hline $\begin{array}{l}\ln (\text { school }) \\
\text { Percentage of } \\
\text { working age population } \\
\text { in secondary school }\end{array}$ & $\begin{array}{c}0.655 \\
(0.073)\end{array}$ & $\begin{array}{c}0.570 \\
(0.114)\end{array}$ & $\begin{array}{c}0.448 \\
(0.285)\end{array}$ & 0.950 & -1.406 \\
\hline $\begin{array}{l}\text { Zero sum hypothesis } \\
\text { sum } \\
\text { t-statistic }\end{array}$ & $\begin{array}{l}-0.393 \\
(0.457) \\
-0.860\end{array}$ & $\begin{array}{l}-1.849 \\
(0.715) \\
-2.586\end{array}$ & $\begin{array}{l}-1.306 \\
(1.195) \\
-1.092\end{array}$ & & \\
\hline Joint EV tests on all var & riables & & & $\begin{array}{c}\mathrm{p} \text {-value } \\
0.009\end{array}$ & $\begin{array}{c}\text { p-value } \\
0.002\end{array}$ \\
\hline
\end{tabular}

\section{B) Restricted Set of Instruments}

\begin{tabular}{lccccc}
\hline Constant & 6.848 & 3.692 & 1.219 & & \\
& $(1.177)$ & $(1.755)$ & $(2.046)$ & & \\
& & & & & \\
$\ln (\mathrm{I} / \mathrm{GDP})$ & 0.697 & 0.630 & 0.577 & 0.955 & -1.900 \\
& $(0.133)$ & $(0.154)$ & $(0.165)$ & & \\
$\ln (\mathrm{n}+\mathrm{g}+\delta)$ & & & & & \\
& -1.744 & -2.877 & -3.765 & 2.411 & 2.908 \\
& $(0.416)$ & $(0.617)$ & $(0.718)$ & & \\
$\ln ($ school $)$ & 0.655 & 0.642 & 0.631 & 0.956 & -0.053 \\
& $(0.073)$ & $(0.072)$ & $(0.076)$ & &
\end{tabular}

Zero sum hypothesis

$\begin{array}{llll}\text { sum } & -0.393 & -1.606 & -2.556 \\ & (0.457) & (0.682) & (0.797) \\ \text { t-statistic } & -0.860 & -2.355 & -3.206\end{array}$




\title{
Liste des publications au CIRANO *
}

\author{
Série Scientifique / Scientific Series (ISSN 1198-8177)
}

\author{
96s-14 Numerical Methods for Pricing Derivative Securities / Mark Broadie et Jérôme Detemple \\ 96s-13 Monitoring New Technological Developments in the Electricity Industry : An \\ International Perspective / Louis A. Lefebvre, Élisabeth Lefebvre et Lise Préfontaine \\ 96s-12 Model Error in Contingent Claim Models Dynamic Evaluation / Eric Jacquier et Robert \\ Jarrow \\ 96s-11 Mesures de la croissance de la productivité dans un cadre d'équilibre général : L'Économie \\ du Québec entre 1978 et 1984 / Pierre Mohnen, Thijs ten Raa et Gilles Bourque \\ 96s-10 The Efficiency of Collective Bargaining in Public Schools / Daniel S. Hosken et David N. \\ Margolis \\ 96s-09 Constant Consumption and the Economic Depreciation of Natural Capital : The Non- \\ Autonomous Case / John M. Hartwick et Ngo Van Long \\ 96s-08 Upstream-Downstream Specialization by Integrated Firms in a Partially Integrated \\ Industry / Gérard Gaudet, Ngo Van Long et Antoine Soubeyran \\ 96s-07 Toward a Political Theory of Environmental Policy / Marcel Boyer et Jean-Jacques \\ Laffont \\ 96s-06 Work Sharing and Producrivity : Evidence from a Natural Experiment / Paul Lanoie, \\ François Raymond et Bruce Shearer \\ 96s-05 Claims Reporting and Risk Bearing Moral Hazard in Workers' Compensation : The \\ Canadian Context / Guylaine Baril et Paul Lanoie \\ 96s-04 The Determinants of University Dropouts : A Sequential Decision Model with Selectivity \\ Bias / Claude Montmarquette, Sophie Mahseredjian et Rachel Houle \\ 96s-03 Solutions au stress financier : Un survol de la littérature / Jocelyn Martel \\ 96s-02 The Politics and Regulation of Hydroelectricity : The Case of Quebec in the Thirties / Ruth \\ Dupré, Michel Patry et Patrick Joly \\ 96s-01 Cognition in Seemingly Riskless Choices and Judgments / Louis Lévy-Garboua et Claude \\ Montmarquette \\ 95s-51 Entry Blockading Locations / Marcel Boyer, Philippe Mahenc et Michel Moreaux \\ 95s-50 Environmental Protection, Producer Insolvency and Lender Liability / Marcel Boyer et \\ Jean-Jacques Laffont \\ 95s-49 Stochastic Volatility / Eric Ghysels, Andrew Harvey et Eric Renault \\ 95s-48 Is Workers' Compensation Disguised Unemployment Insurance? / Bernard Fortin, Paul \\ Lanoie et Christine Laporte \\ 95s-47 Asset and Commodity Prices with Multiattribute Durable Goods / Jérôme Detemple et \\ Christos I. Giannikos \\ 95s-46 Cohort Effects and Returns to Seniority in France / David N. Margolis
}

\footnotetext{
*Vous pouvez consulter la liste complète des publications du CIRANO et les publications elles-mêmes sur notre site World Wide Web à l'adresse suivante :

http://www.cirano.umontreal.ca/publication/page1.html
} 